\title{
البـثن النغالث:
}

أثر التدريس باستخدام الفصل الافتراضي المتراهن في تقدير الذات إنات إنوات والاتجاه نهو التعلم هن خلاله لدى طلاب الدبلئم الخاص في الداص

\section{:}

د/ وفاء صلاح الدين إبراهيم الدسوقي

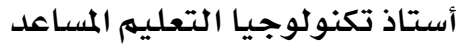

بكلية التربية النوعية جامعة المعنيا 



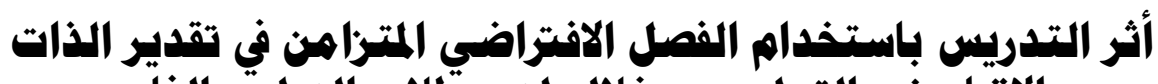

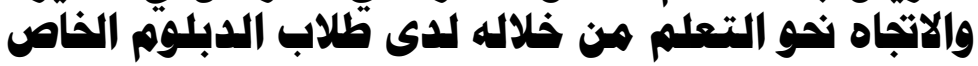 د/ وفاء صلاح اللدين إيراهيم الدسوقي}

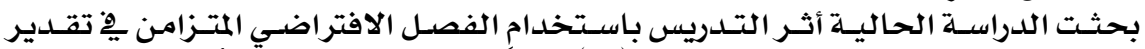

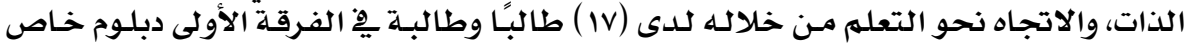

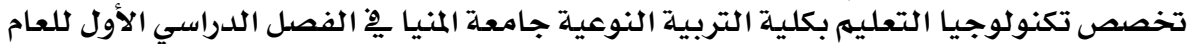

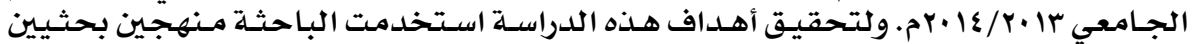

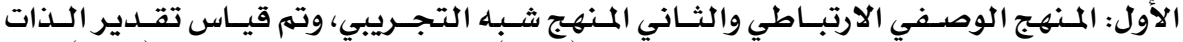

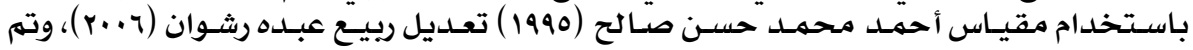

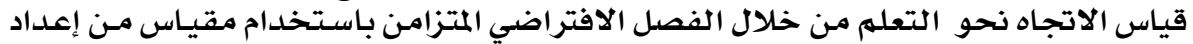

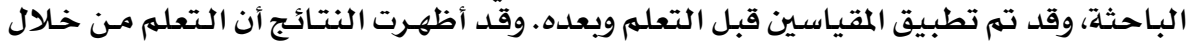

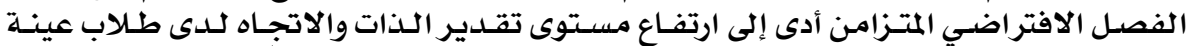

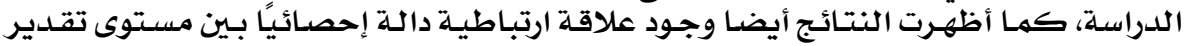

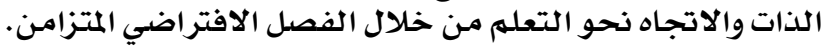

الكلمات المفتاحية: الفصل الافتراضي المتزامن ، تقدير الذات ، الاتجاه

The effect of teaching with the use of Synchronous Virtual Classroom on self-esteem and learning attitude of private diploma students

\section{Wafaa Salah Eldin Ibrahim Eldessouki}

\section{Abstract:}

The current study investigated the effect of teaching with the use of synchronous virtual classroom on self-esteem and learning attitude which is based on synchronous virtual classroom. The participants are 17 first year students of private diploma at faculty of specific education, Minia University. These students are specialized in instruction technology. The study was conducted in the first semester of the academic year 2013/2014. To achieve the aims of this study, the researcher used two research methods: the quasi-experimental method and the associative descriptive method. Self-esteem was measured using Ahmed Mohamed Saleh scale (1995) modified by Rebee Abdo Rashwan (2006). Learning attitude was measured through Synchronous Virtual Classroom learning using a scale which was prepared by the researcher. The two scales were applied prelearning and post-learning. Results demonstrated that learning through Synchronous Virtual Classroom leads to raise self-esteem level and learning attitude in the study sample. Also the results showed statistically significant relation between the levels of selfesteem and learning attitude.

Key words:Synchronous Virtual Classroom, Self-esteem, Attitude 


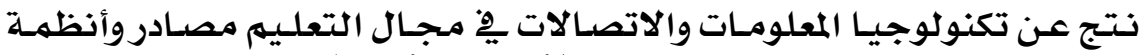

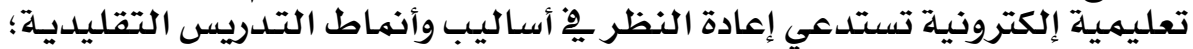

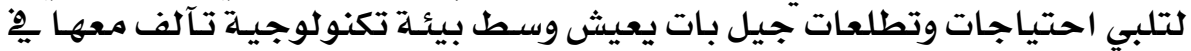

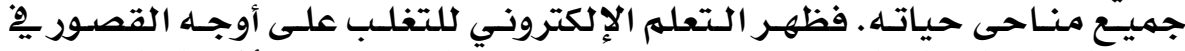

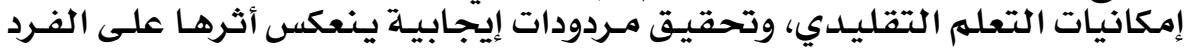

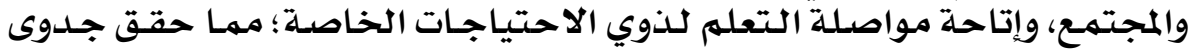

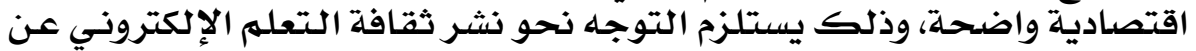

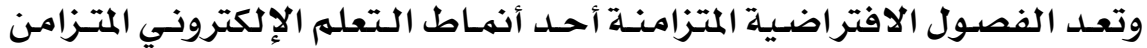

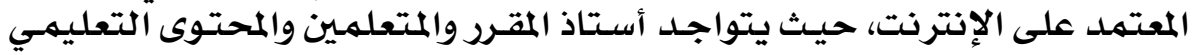

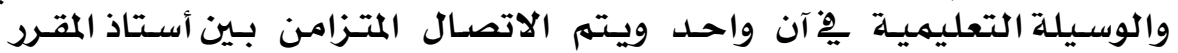

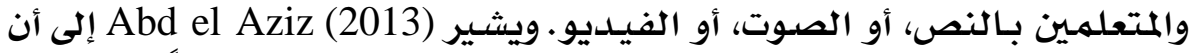

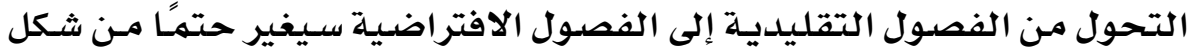

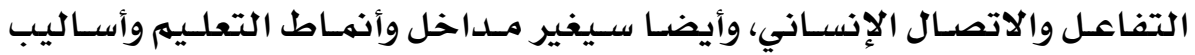

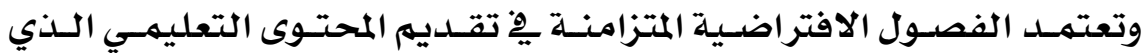

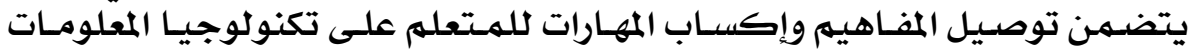

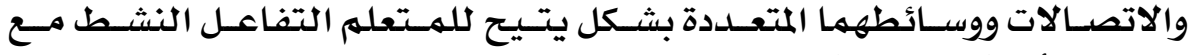

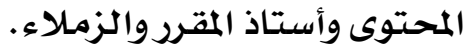

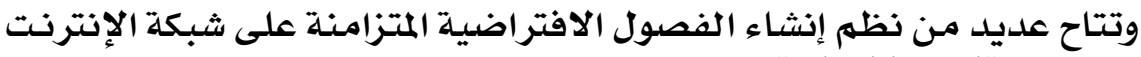

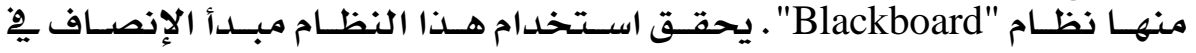

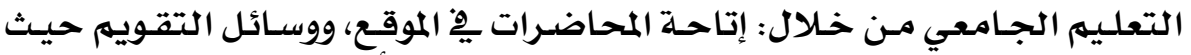

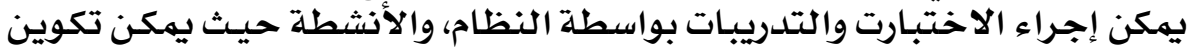

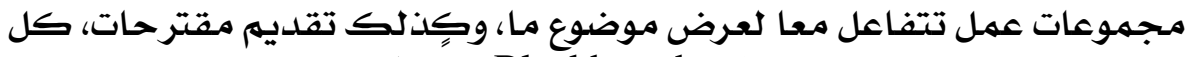

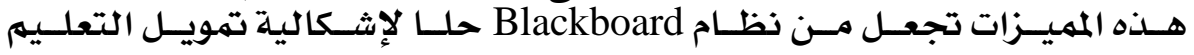

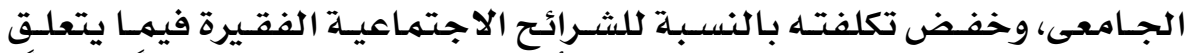

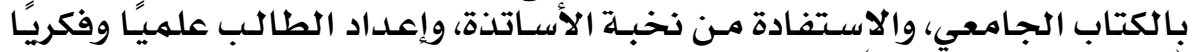

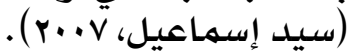

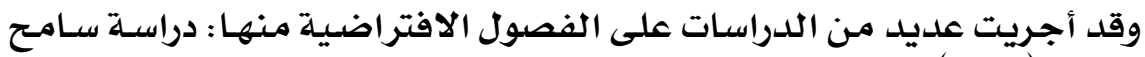

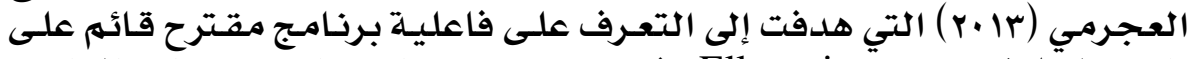

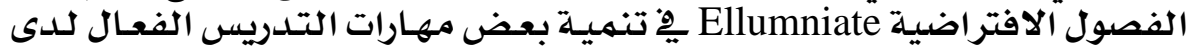

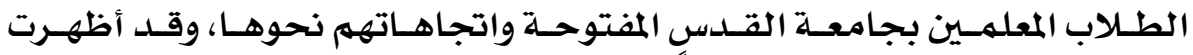

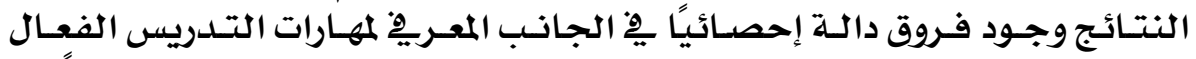

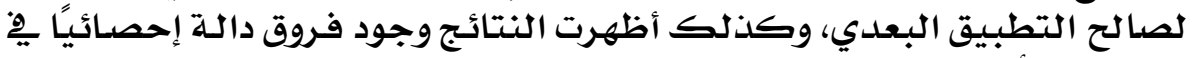

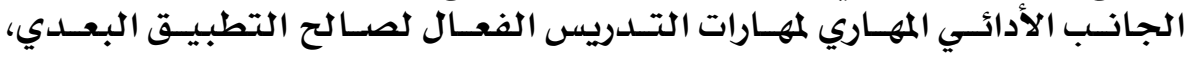




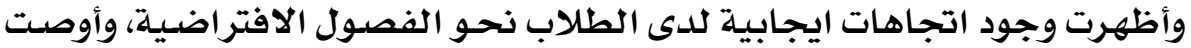

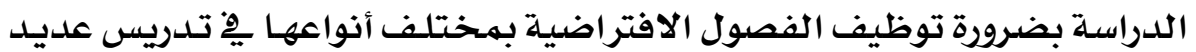

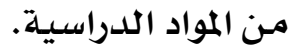

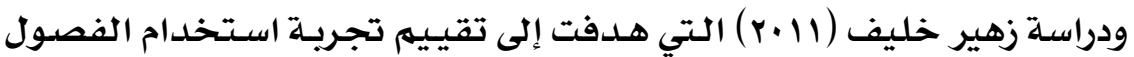

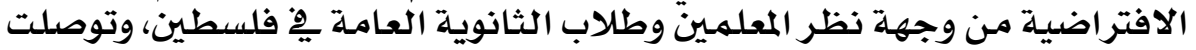

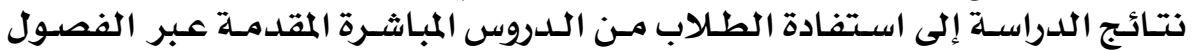

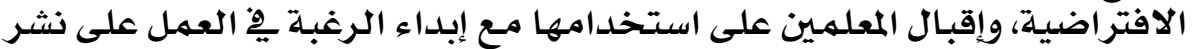

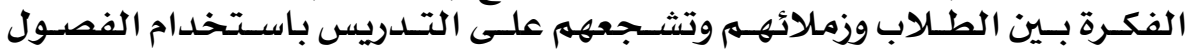

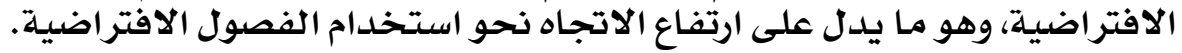

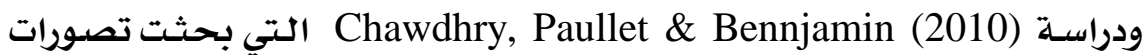

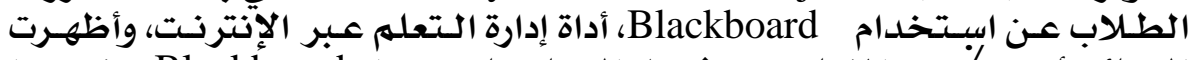

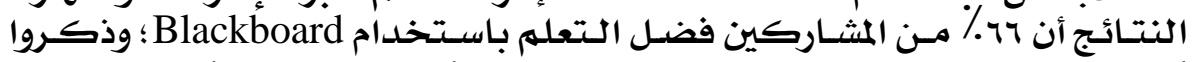

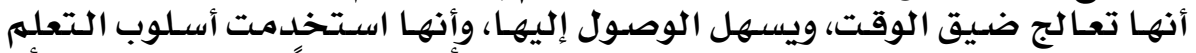

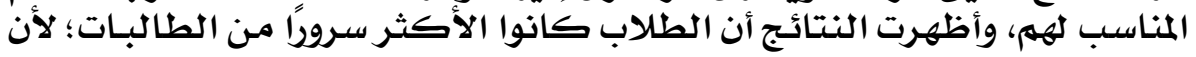

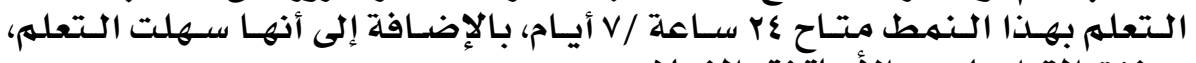

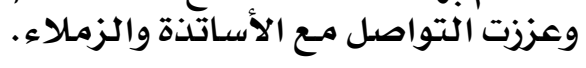

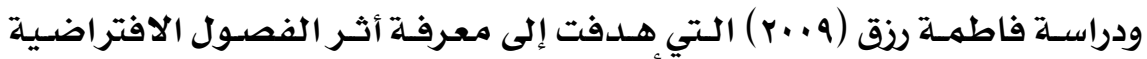

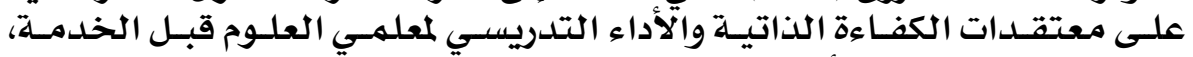

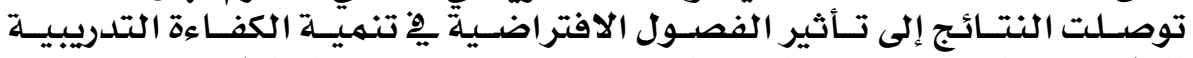

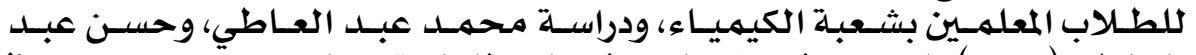

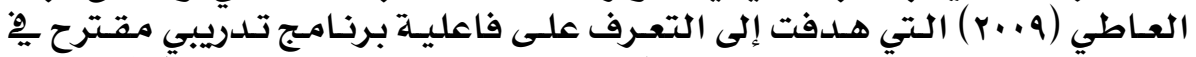

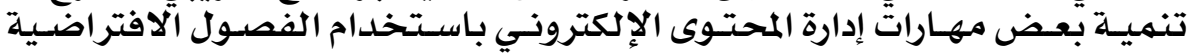

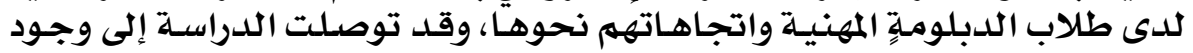

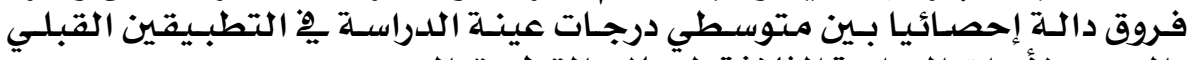

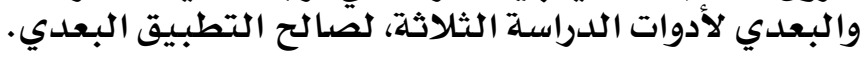

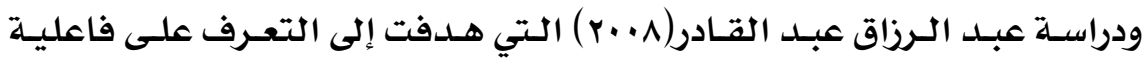

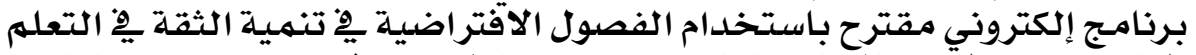

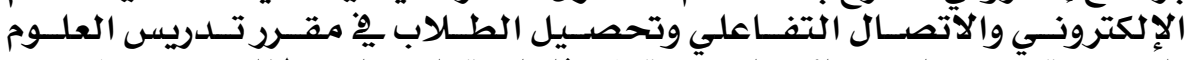

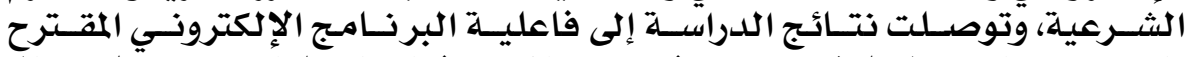

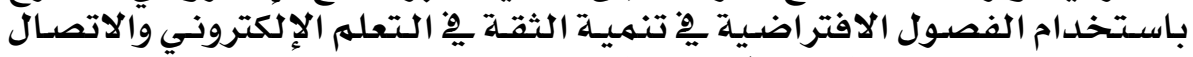

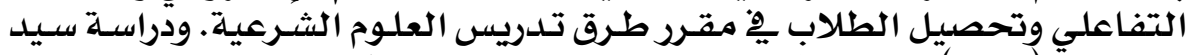

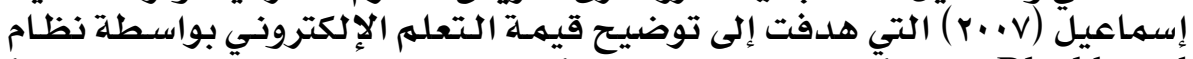

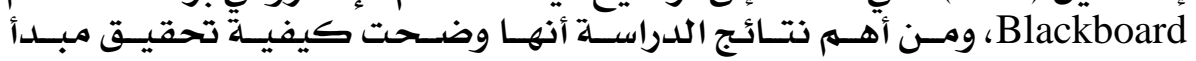

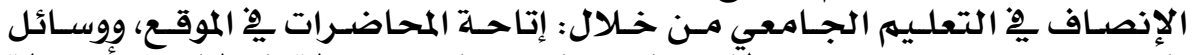

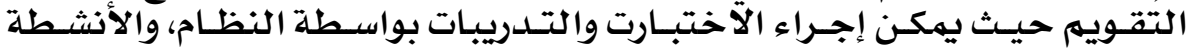

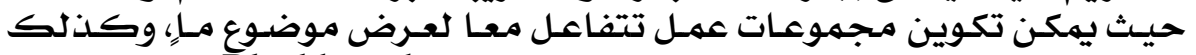

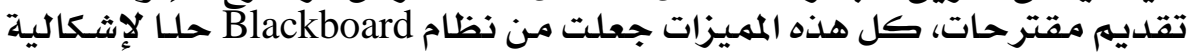

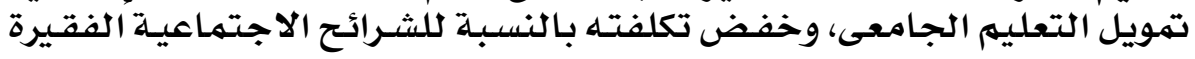




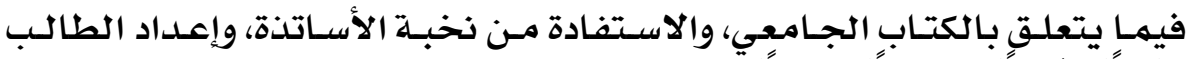

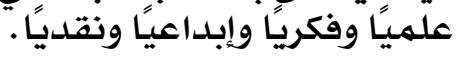

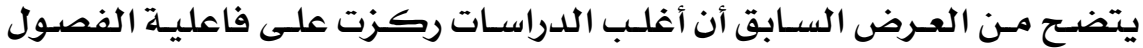

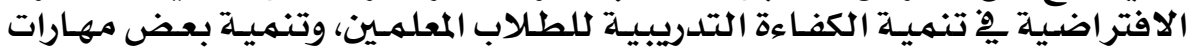

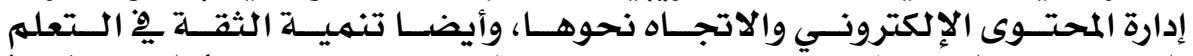

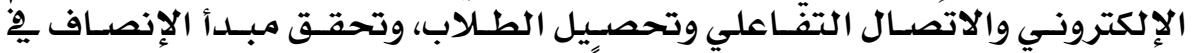

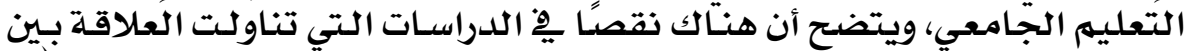

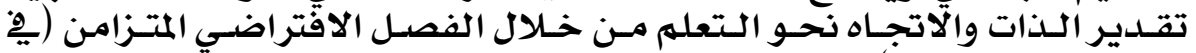

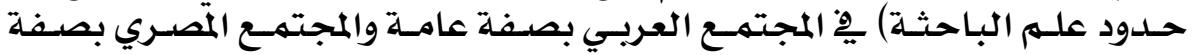

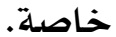

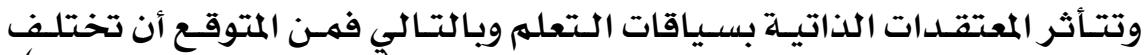

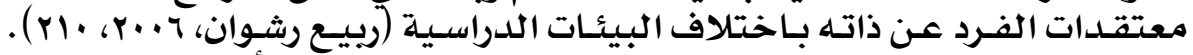

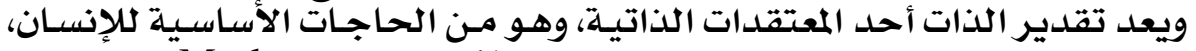

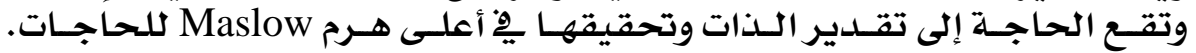

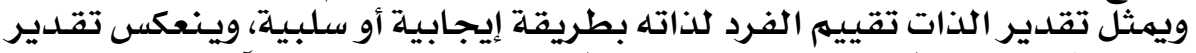

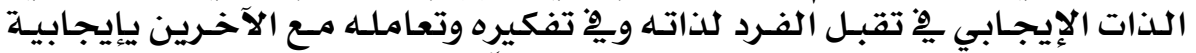

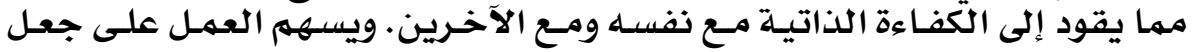

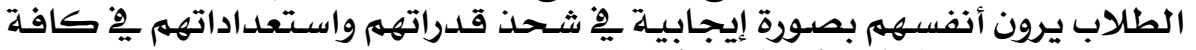

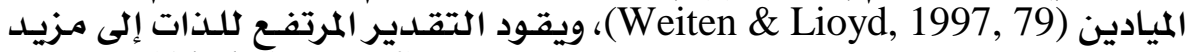

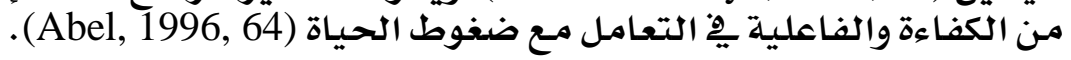

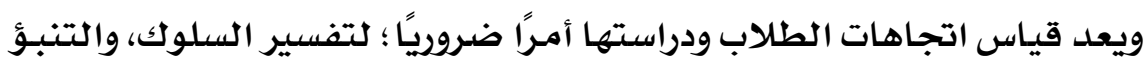

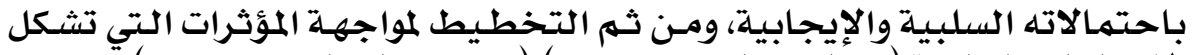

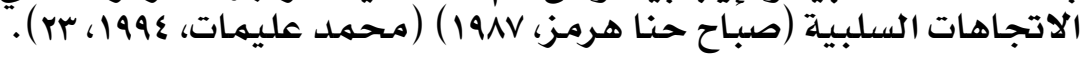

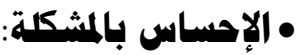

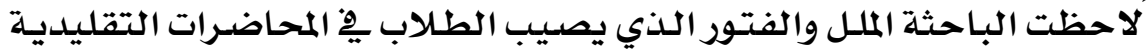

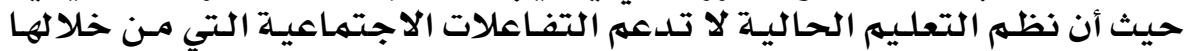

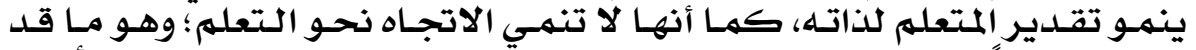

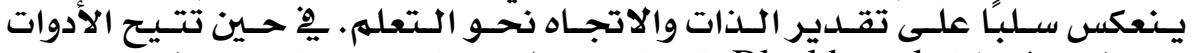

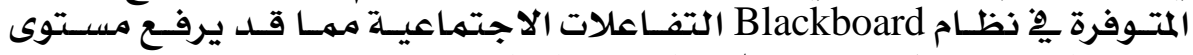
تقدير الذات ومن ثم مستوى نظم الاتجاه نحو التعلهم.

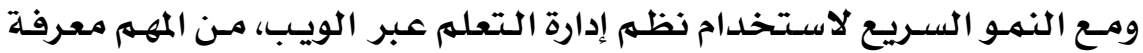

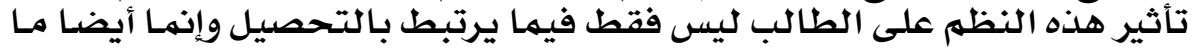

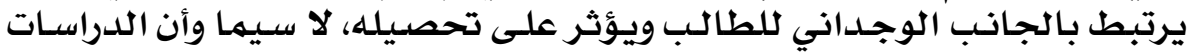

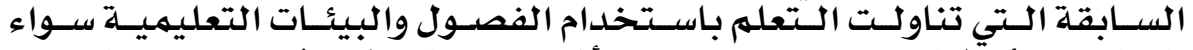

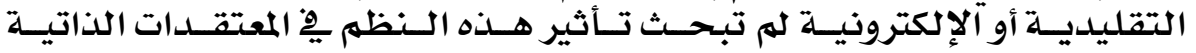

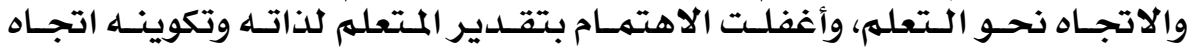

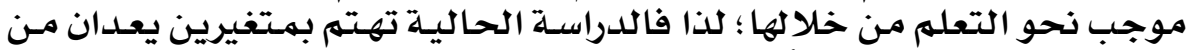

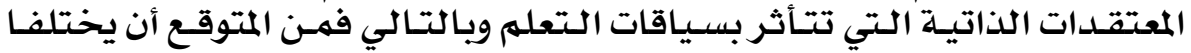




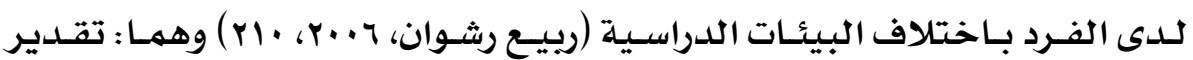

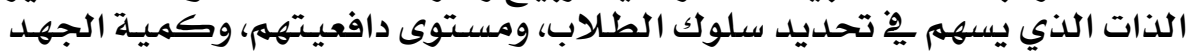

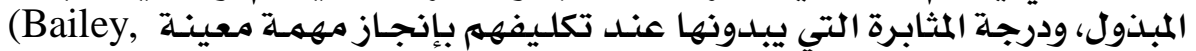

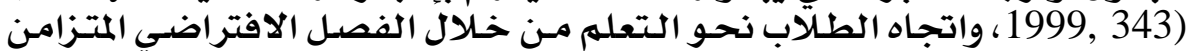

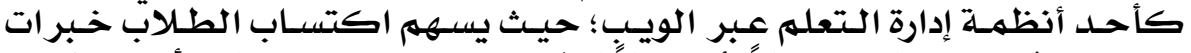

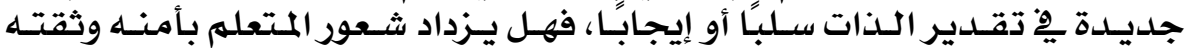

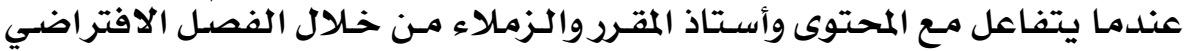

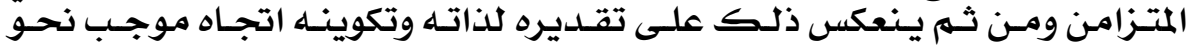

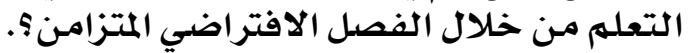

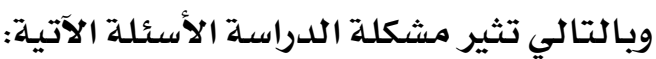

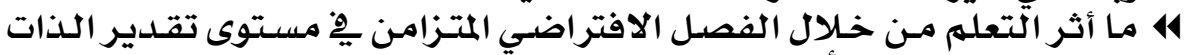

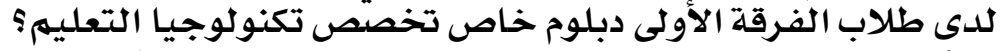

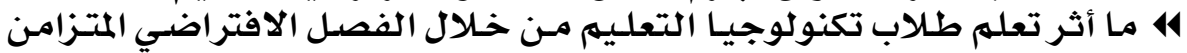

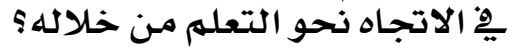
414

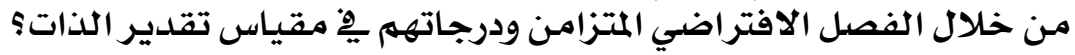

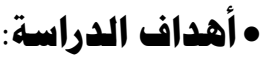

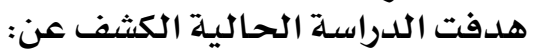

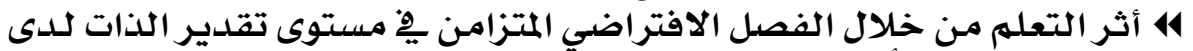

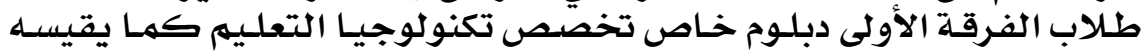

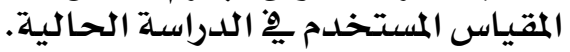

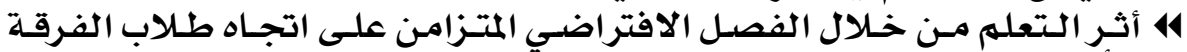

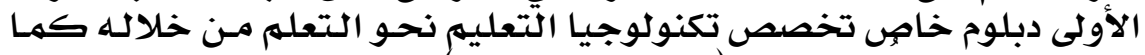

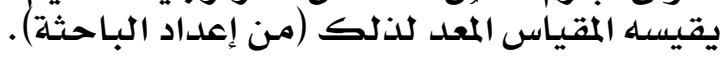

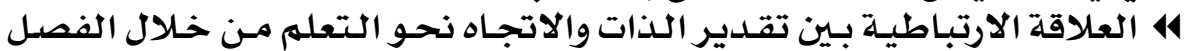

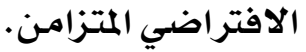
• أهميهة الدراستة:

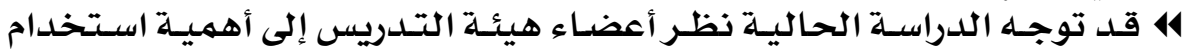

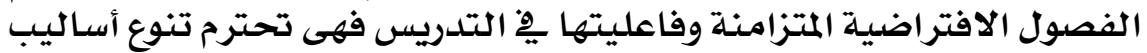

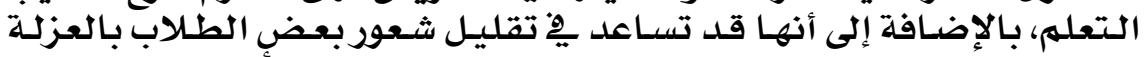

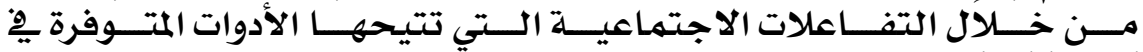

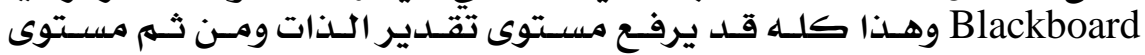
الاتجاه نحو التعلهم من خلاعلا لها.

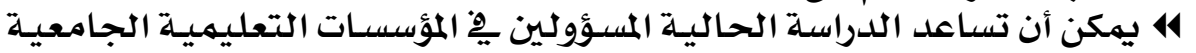

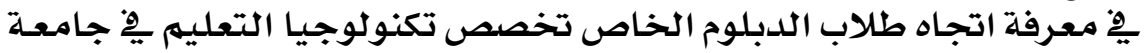

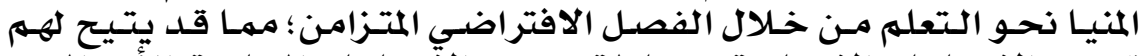

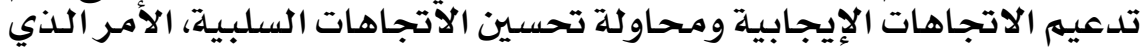

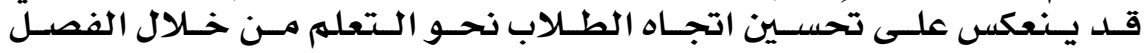

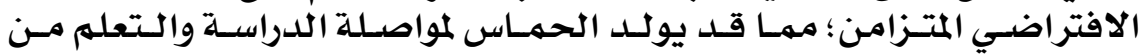


خلالـه، لا سـيما وأن الطـلاب لـديهم إحســاس بـالملـل والفتـور مـن المحاضـرات التقليدية.

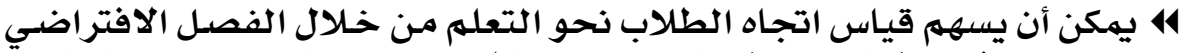

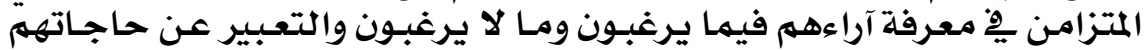

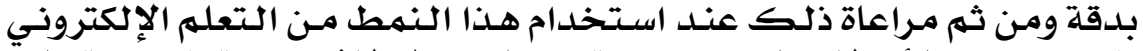

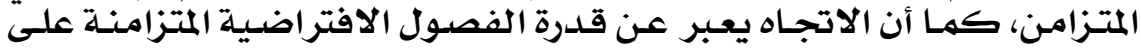

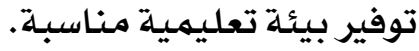

• مغرضيات الدراسية:

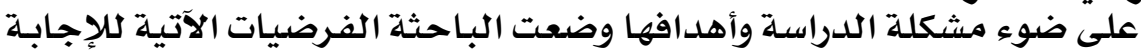

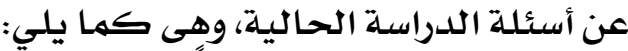

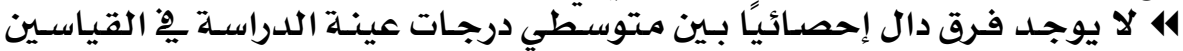

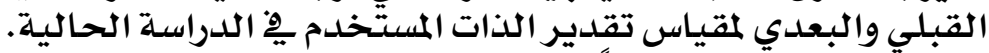

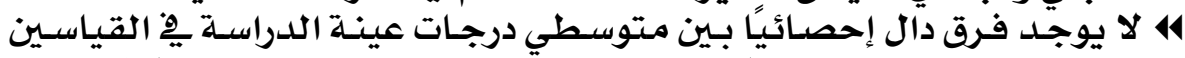

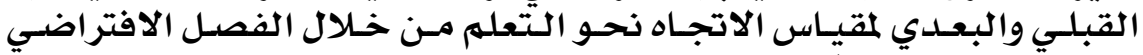

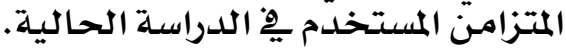

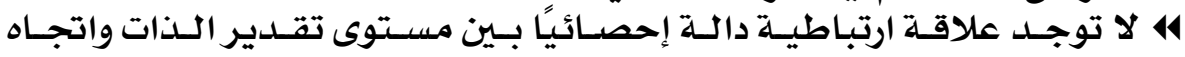

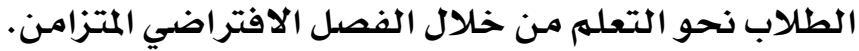

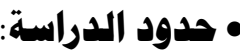

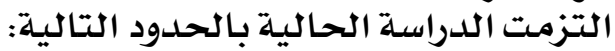

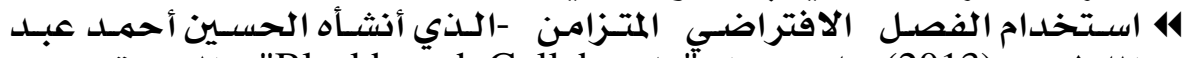

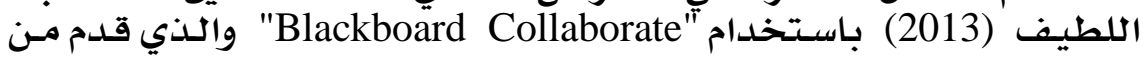

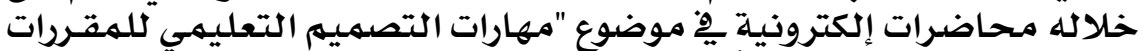

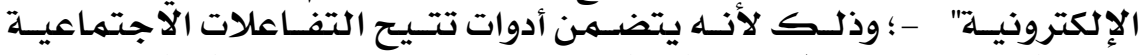

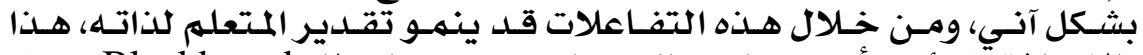

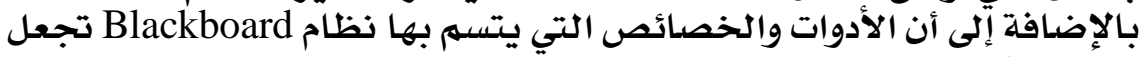

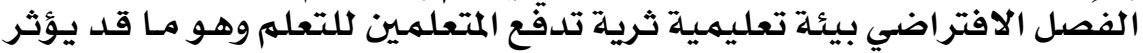

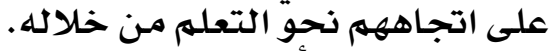

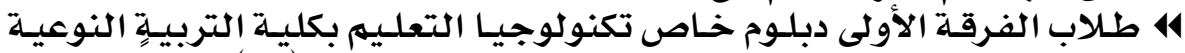

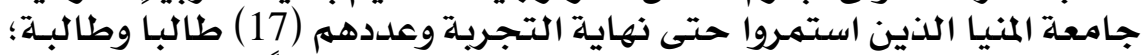

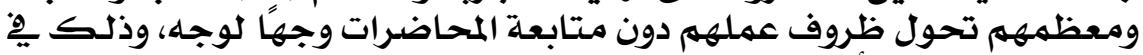

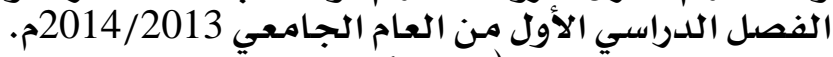

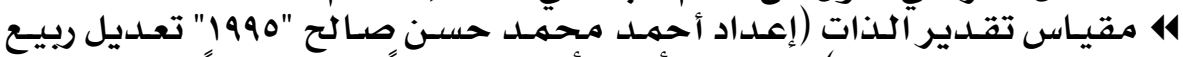

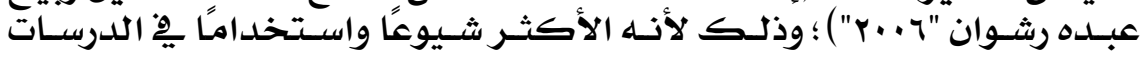

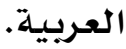
4 هـيـاس الاتجـاه نحـو التتعلهم مـن خـلال الفصـل الافتراضـي المتـزامن (إعـداد الباحثة). • بمطاحات الدراسية:

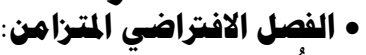

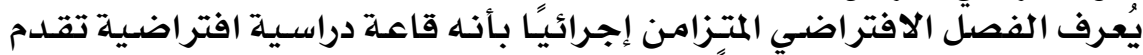

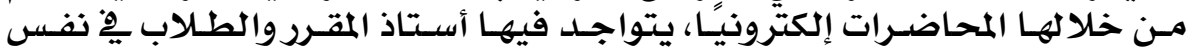

\section{$1 \%$.}




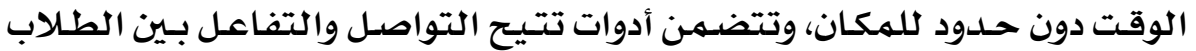

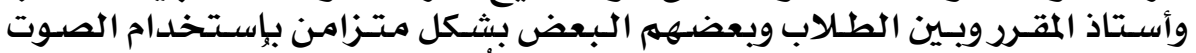

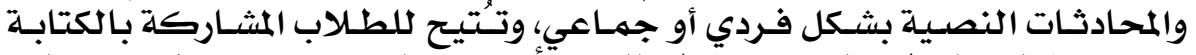

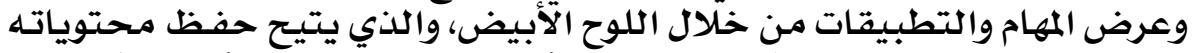

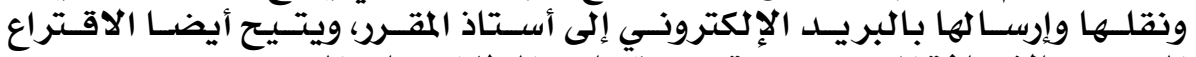

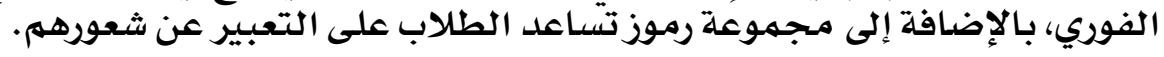

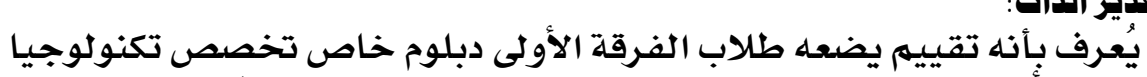

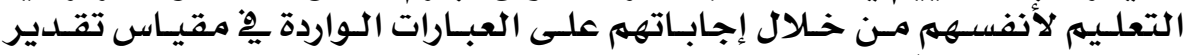

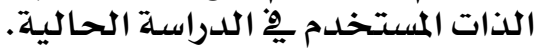

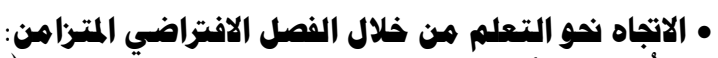

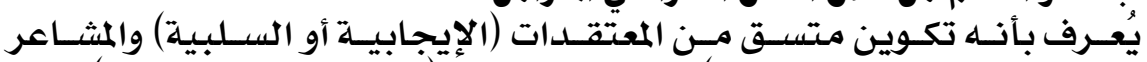

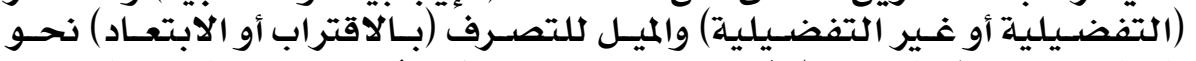

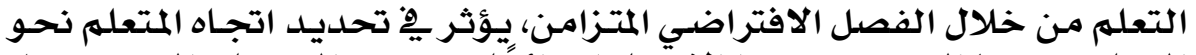

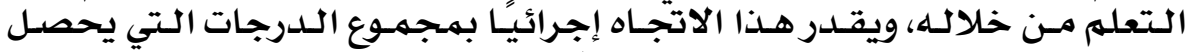

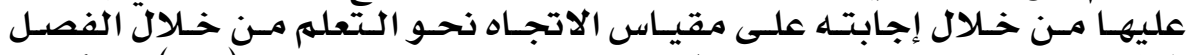

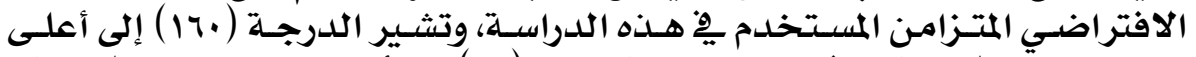

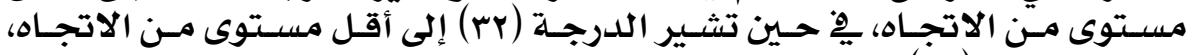

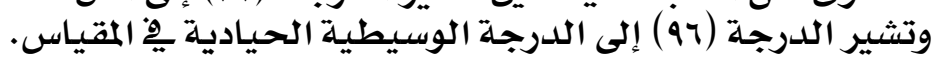

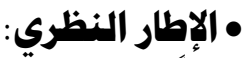

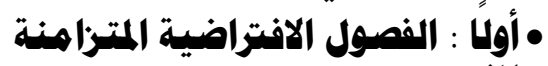

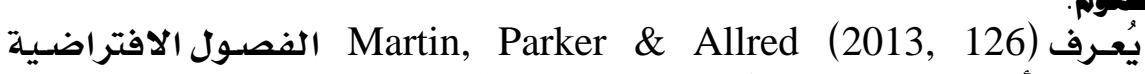

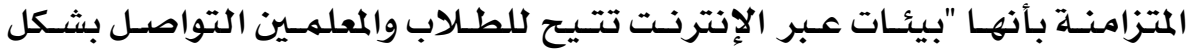

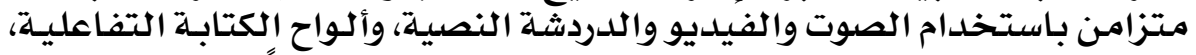

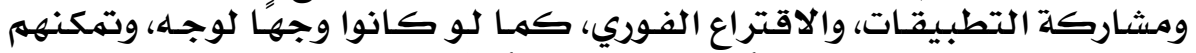

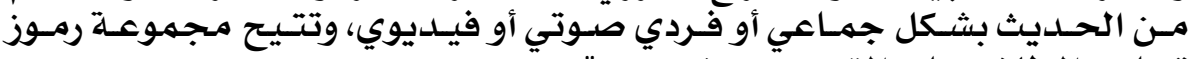

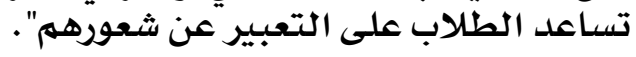

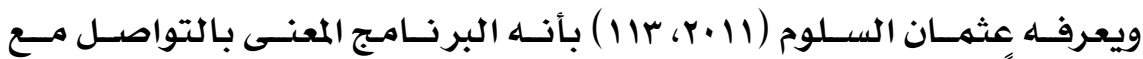

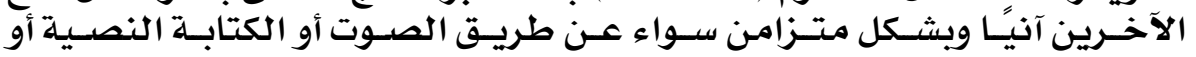

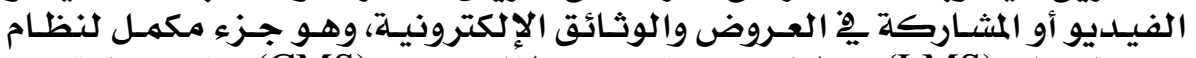

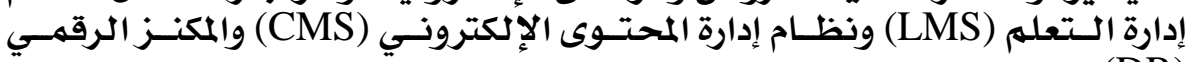
.(DR) الافتراضية وهي: • خصائص الفصول الافنزاضية:

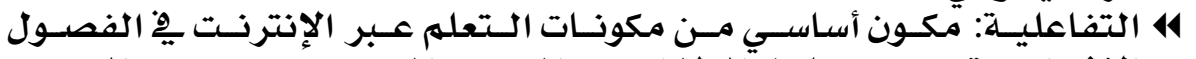

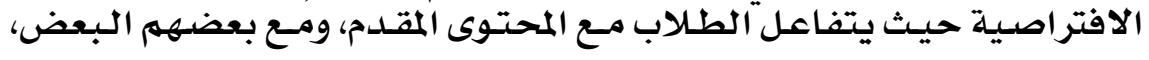


ومـع أسـتاذ المقـرر، ويهكن أن يكون أسـتاذ المقـرروالطلاب ميسـرين يقـدمون

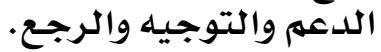

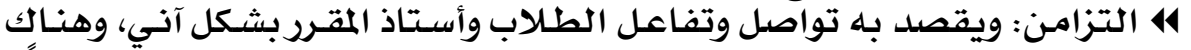

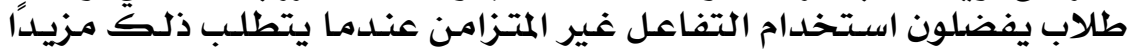
من الاستتقلالية.

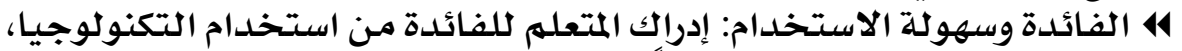

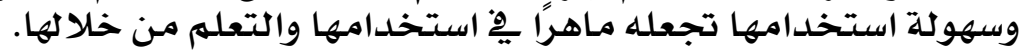

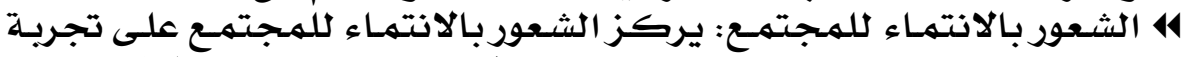

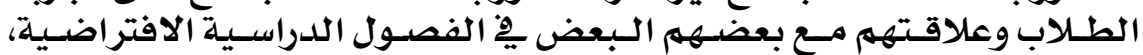

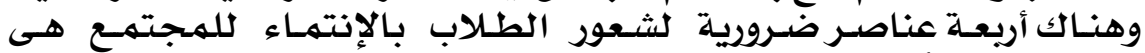

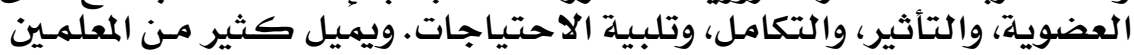

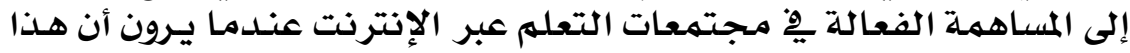

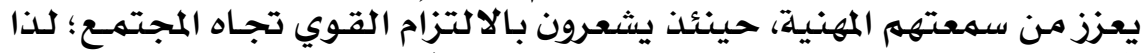

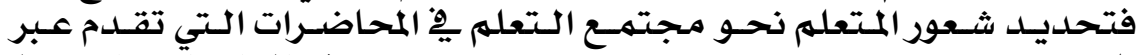

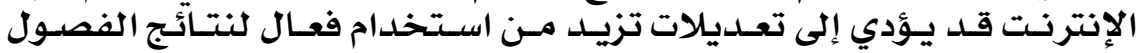
الأفتر اضينة.

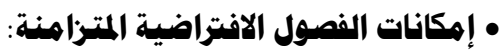

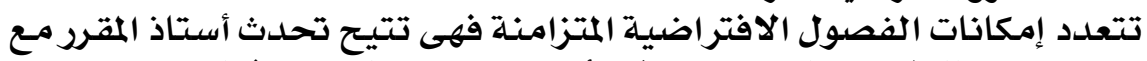

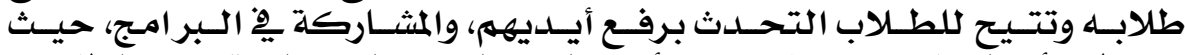

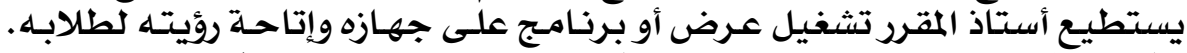

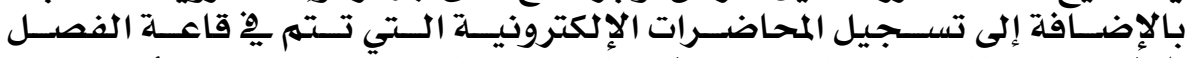

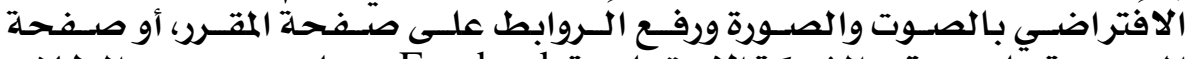

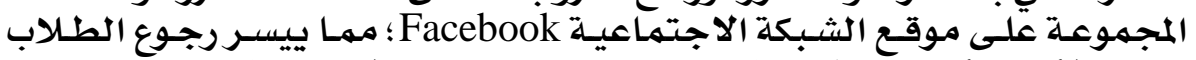

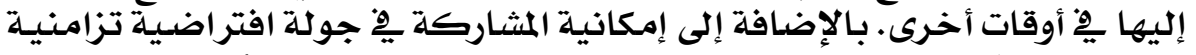

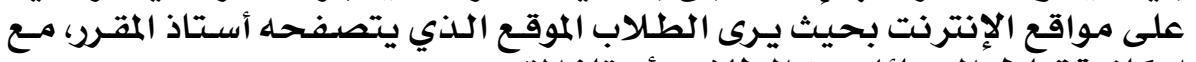

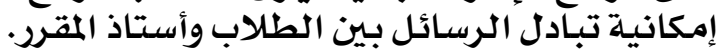

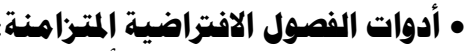

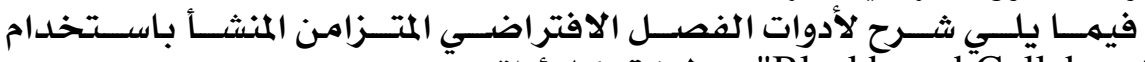
"Blackboard Collaborate"

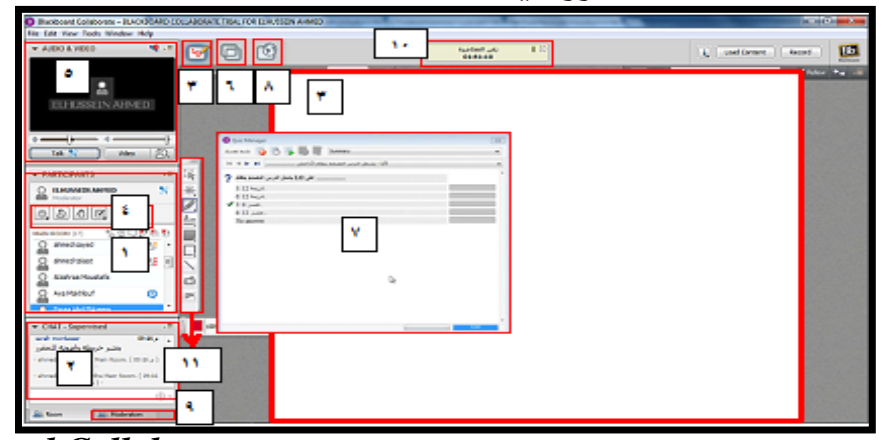

Bكل (1) يوضح ادوات الفصل الافتراضي المتزامن المنشا باستخلام Blackboard Collaborate 


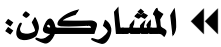

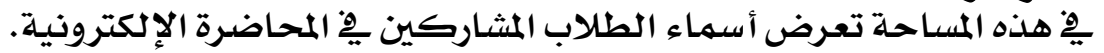

414

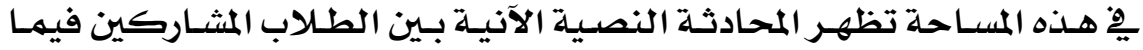

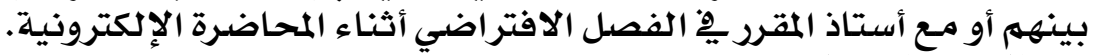

414

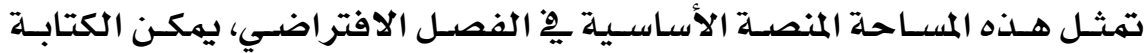

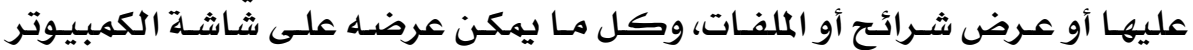

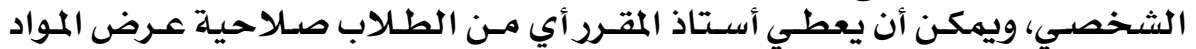

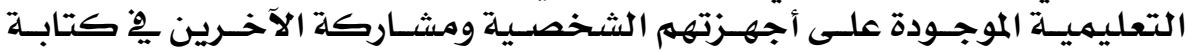

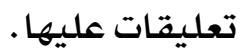

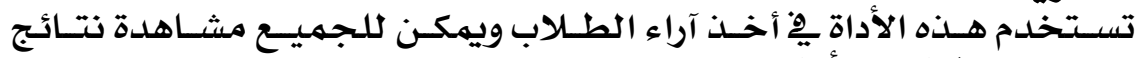

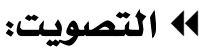
التصويت ومعرفة آراء الأغلبية. 41 البثث الصوتي ومعرة آلمرئي:

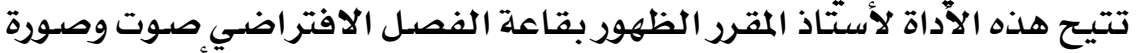

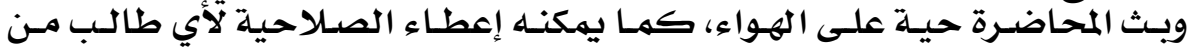

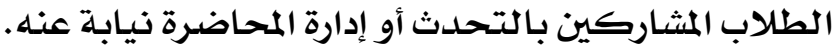

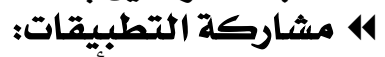

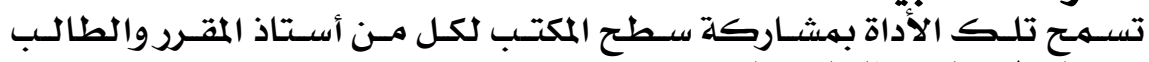

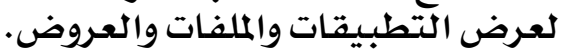

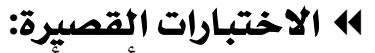

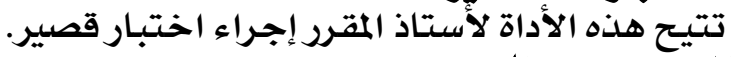
414

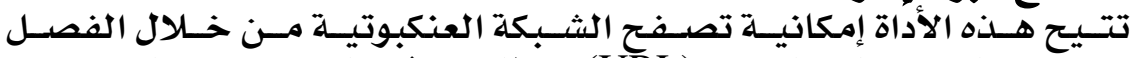

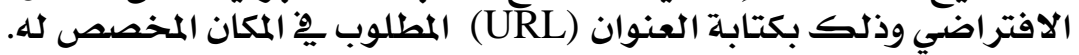

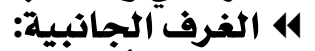

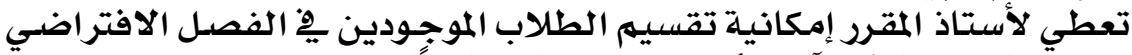

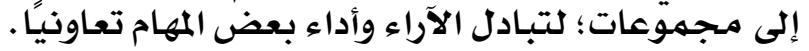

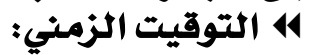

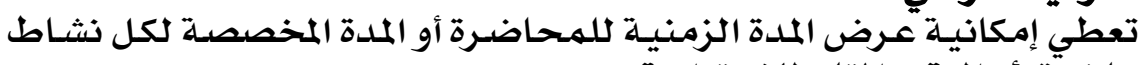
بالمحاضرة، أو الوقت المتتاح للاستراحة المدة النية.

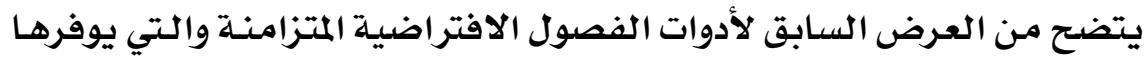

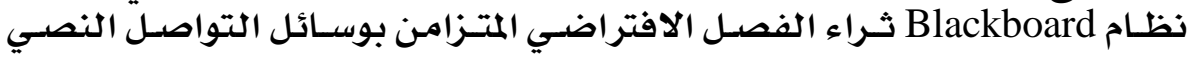

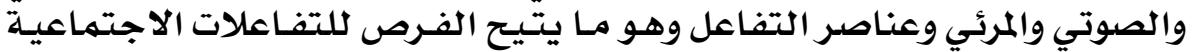

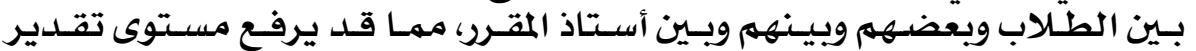

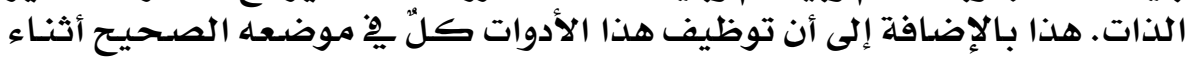

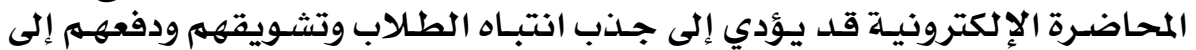

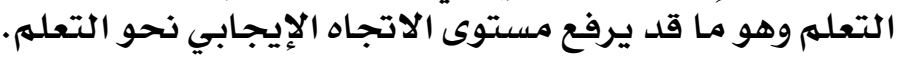

\section{$1 \mathrm{Tr}$}




\section{• متطبات استخدام الفصل الافتراضي المترزاهن:}

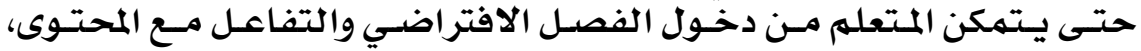

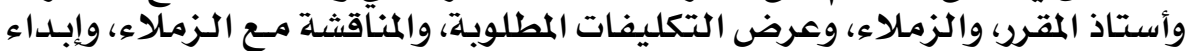
الرأي ينبغي توفر الآتي:

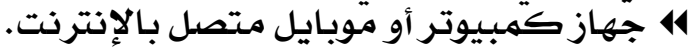

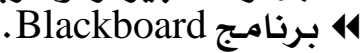
14 14 سميكاعة داخلية.

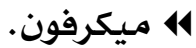
414 يمكن وجوفون كاميرا ويب (له تستخدم يِ الدراسة الحالية).

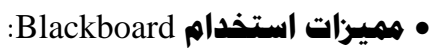

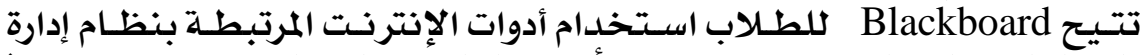

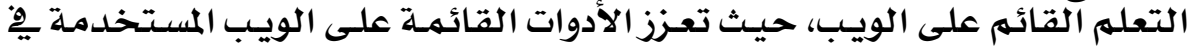

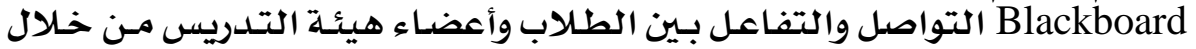

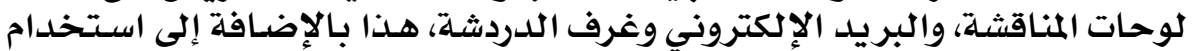

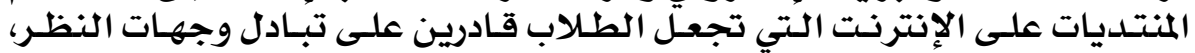

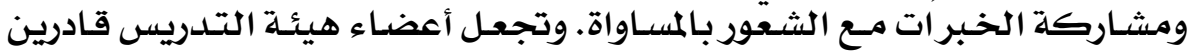

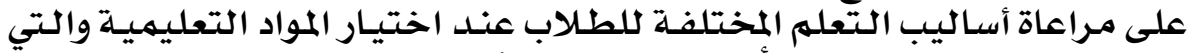

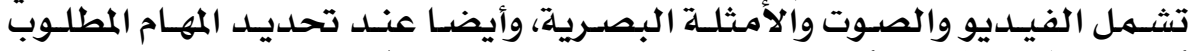

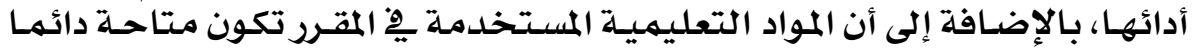

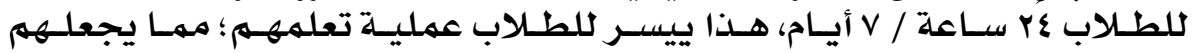

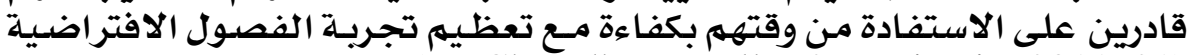
.(In: Chawdhry, Paullet \& Benjamin, 2011, 21)

كما يوفر Blackboard رجـ فوري للطلاب، وتؤكد على وقت المهمدة، وتحترم أساليب التعلم المتنوعة Ballard, Stapleton, \& Carroll, 2004; Bradford et al., 2006-2007; Harrington, Staffo, \& Wright, 2006; Shea, Chun Sau,

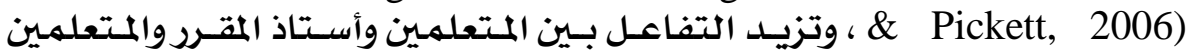

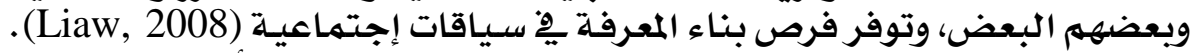

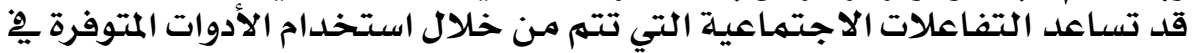

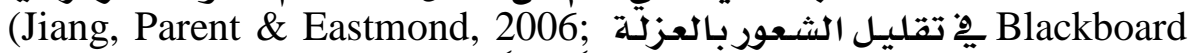

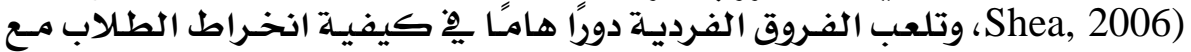
تقنيات الويب (In: Heirdsfield, A Walker, Tambyah \& Beutel, 2011).

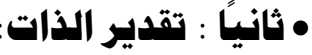

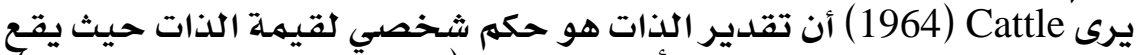

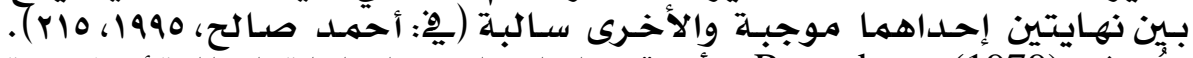

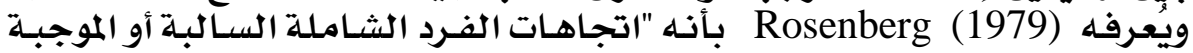

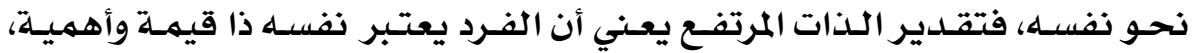

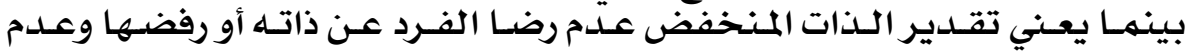

\section{$1 \% \varepsilon$}




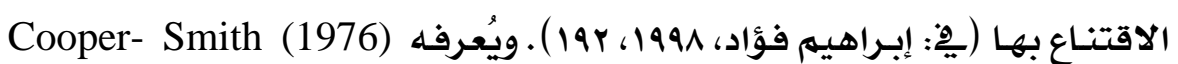

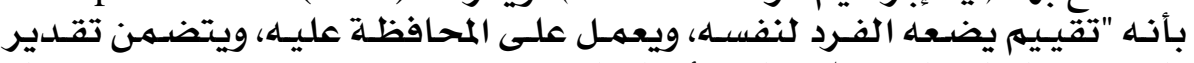

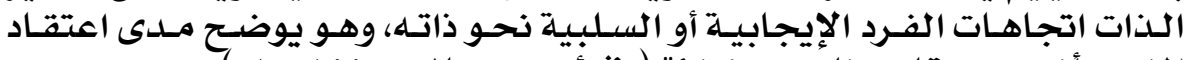

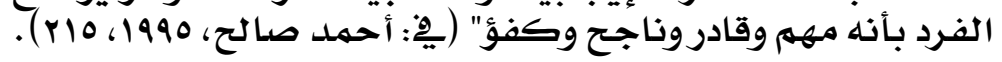

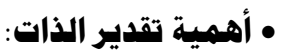

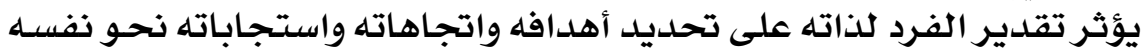

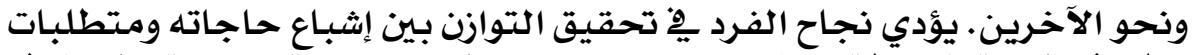

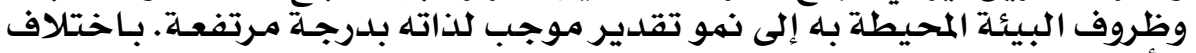

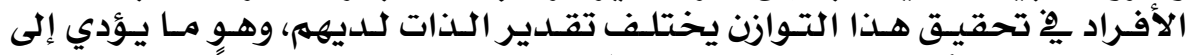

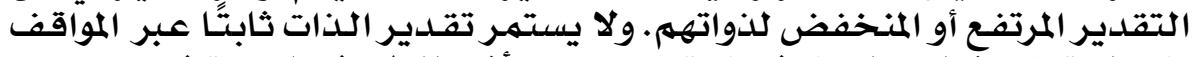

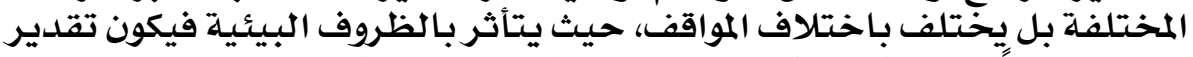

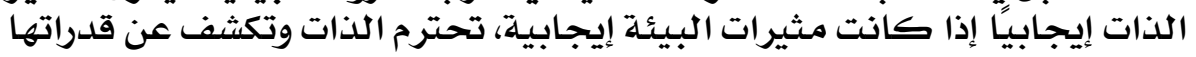

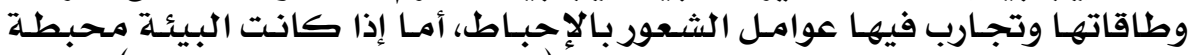

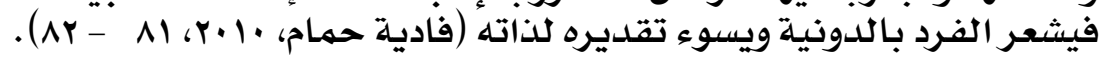

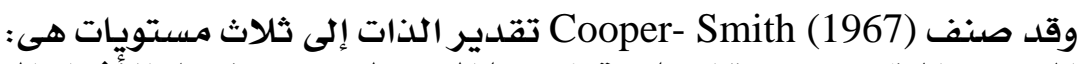

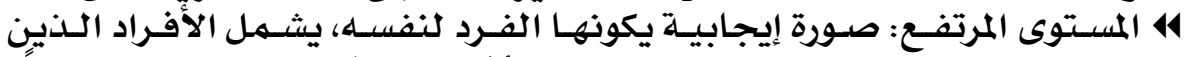

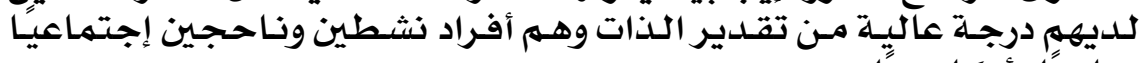

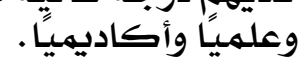

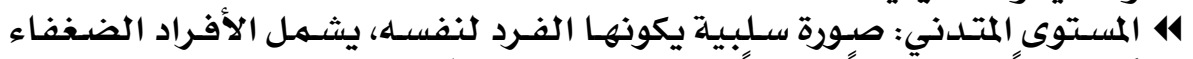

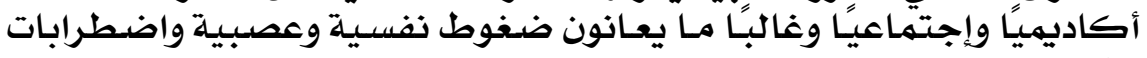
سلوكية.

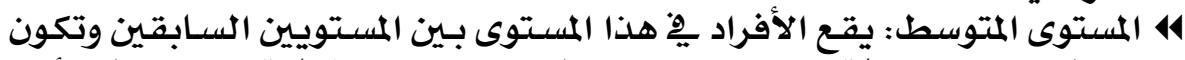

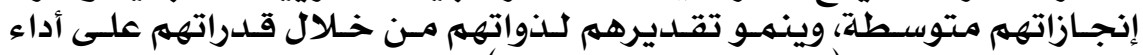

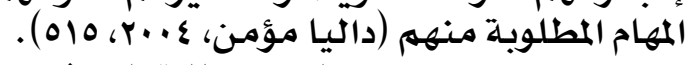

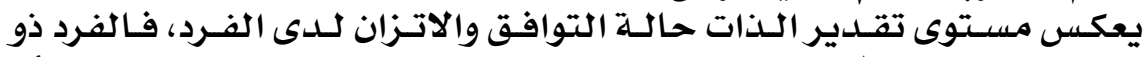

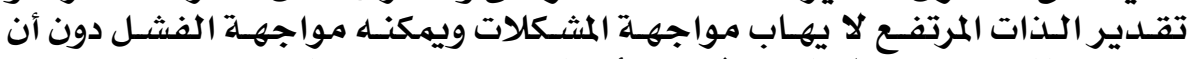

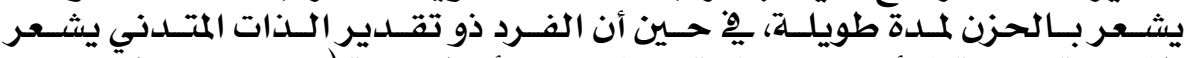

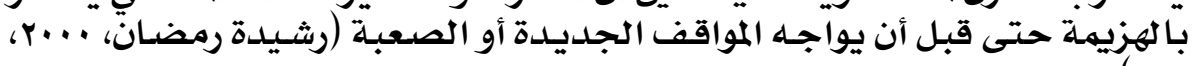
. (r)i

\section{• (نظريات تفسير تقدير الذات:

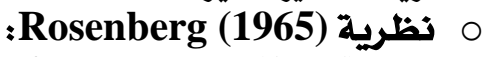

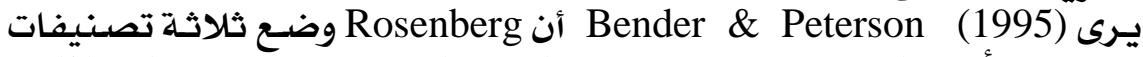

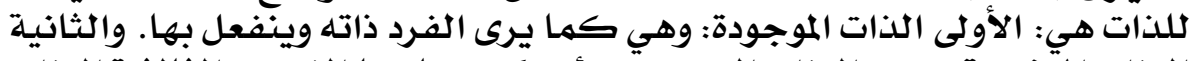

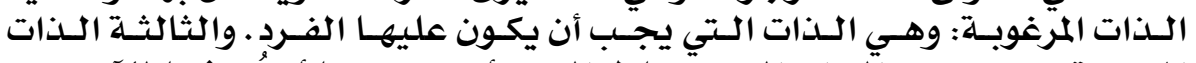

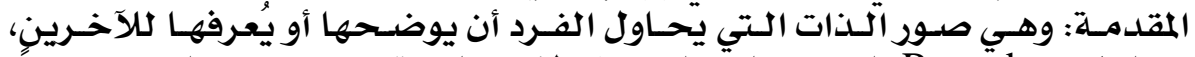

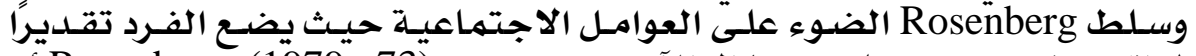

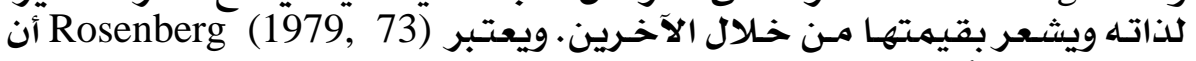

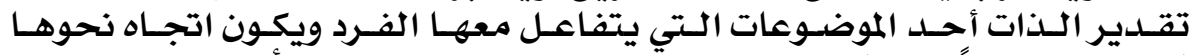

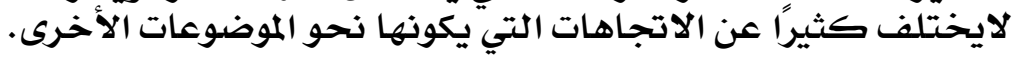

\section{To}




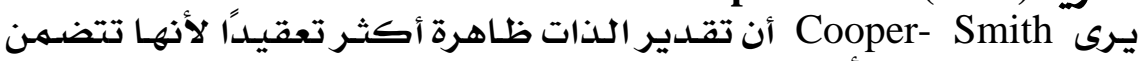

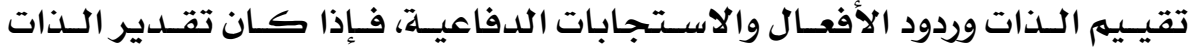

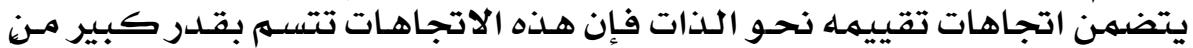

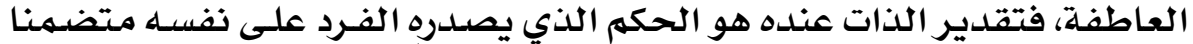

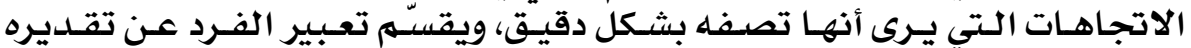

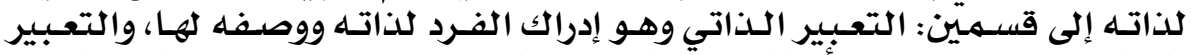

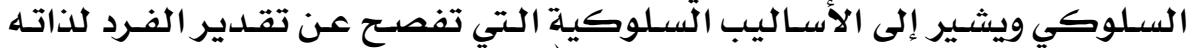

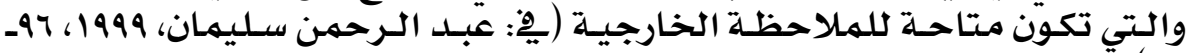

وقد أشار Cooper- Smith إلى أنّ جذور تقدير الذات تكمن بِّ عاملين رئيسـين

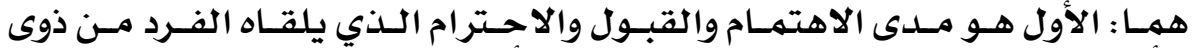

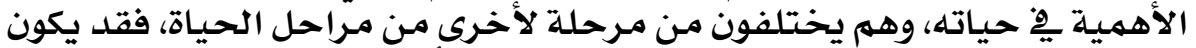

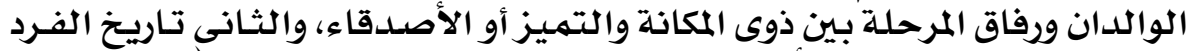

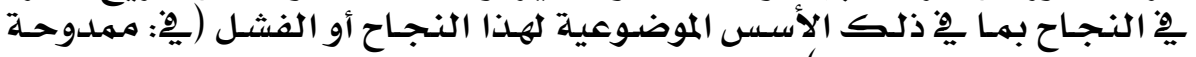
سلامة، (v.r - iva،

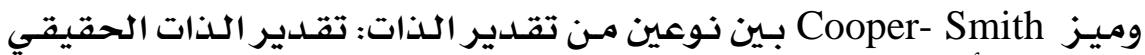

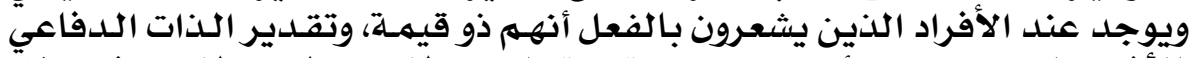

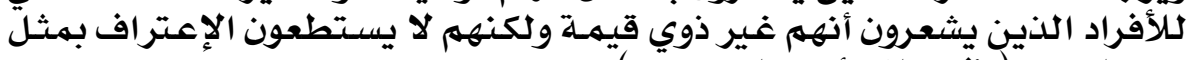

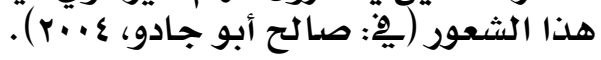

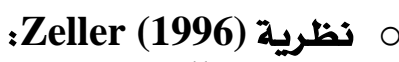
يعتبر مeller تقدير النذات هو البنـاء الاجتهماعي للـذات، وينظر إلى تقدير

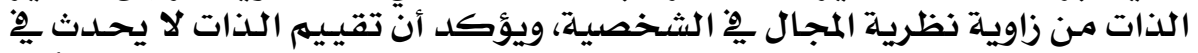

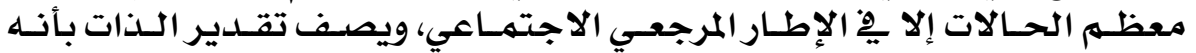

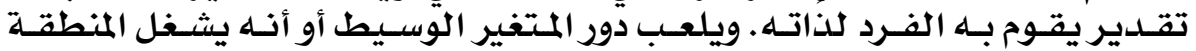

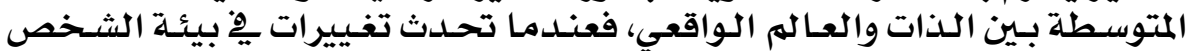

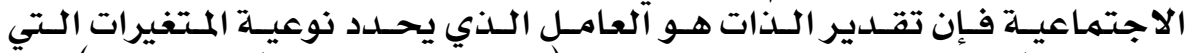

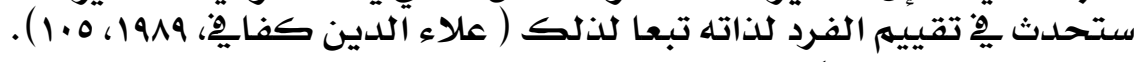

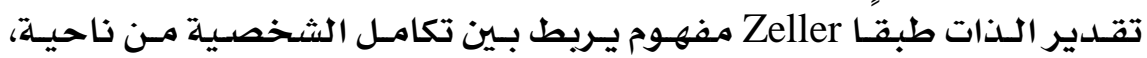

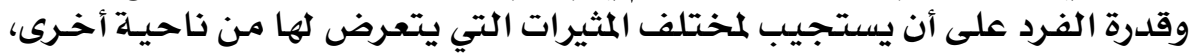

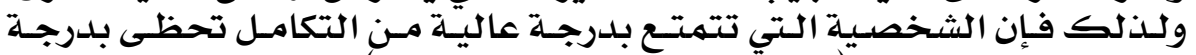

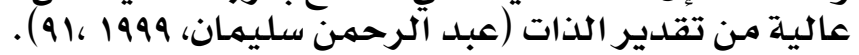

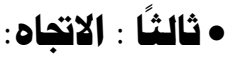

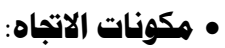

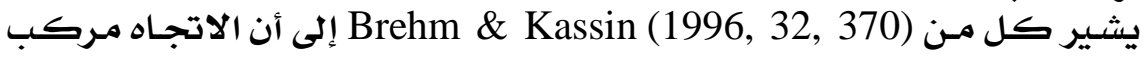
يحتوى على ثلاثة مكونات متسقة وهى كما يلي:

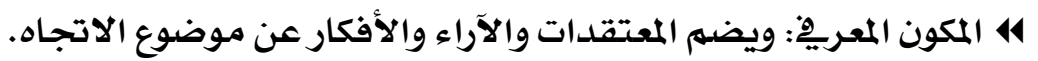


414

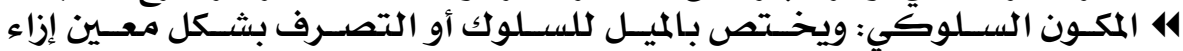

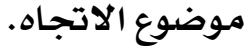

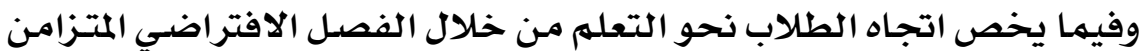

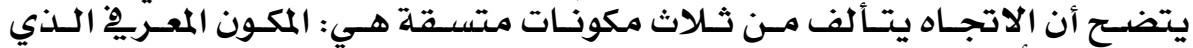

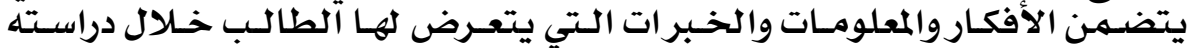

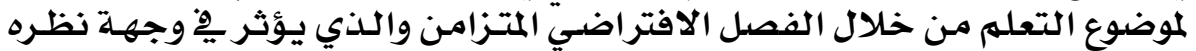

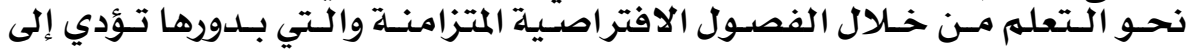

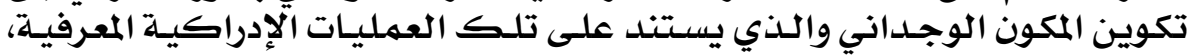

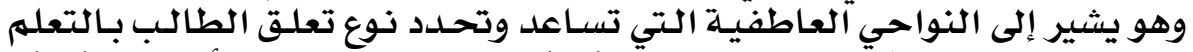

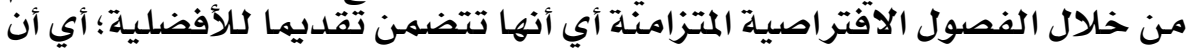

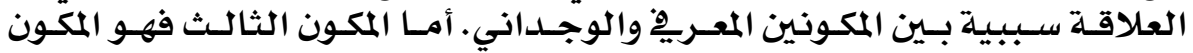

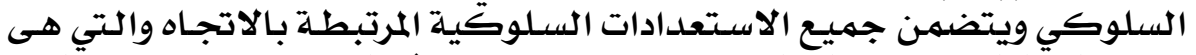

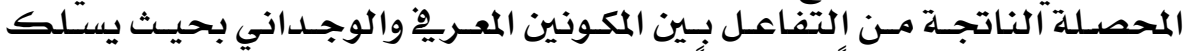

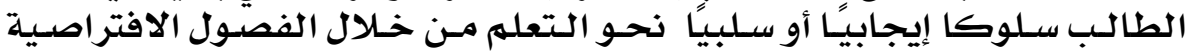

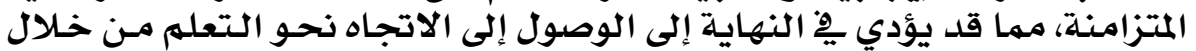

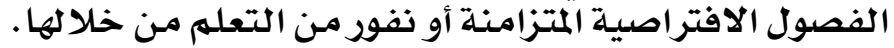

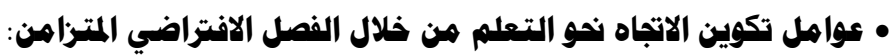

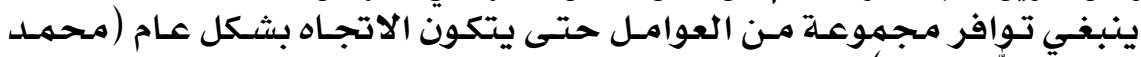

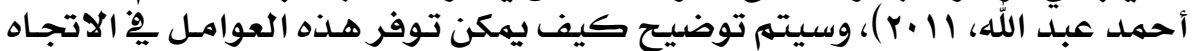

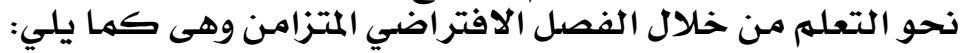

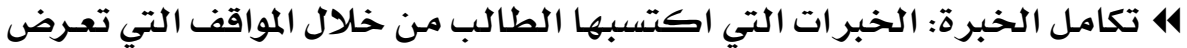

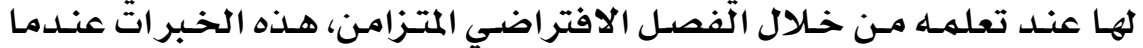

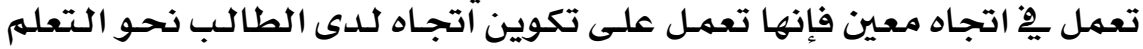

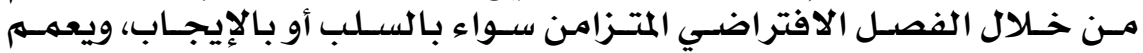

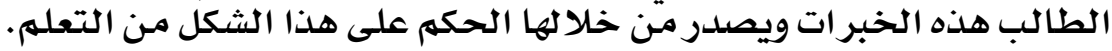

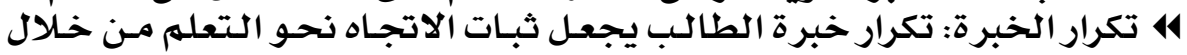

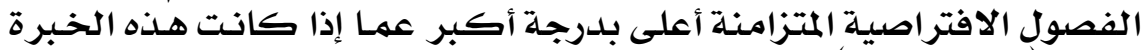

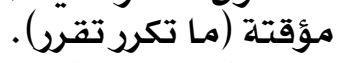

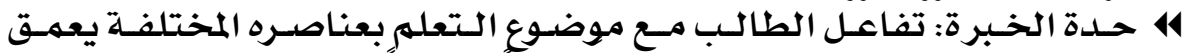

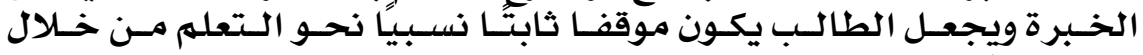
الفصول الافتراصية المبرل المتزامنـة.

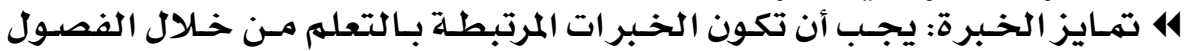

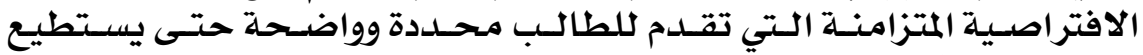

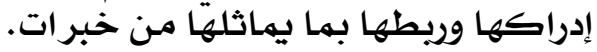

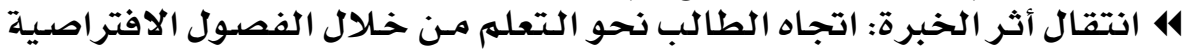

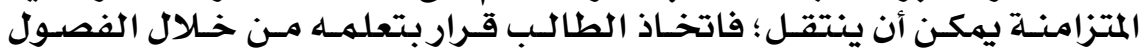

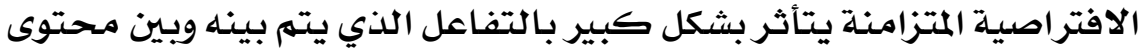

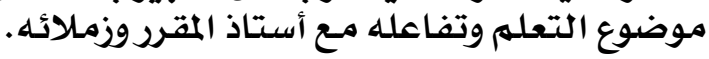

\section{ITV}




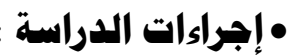

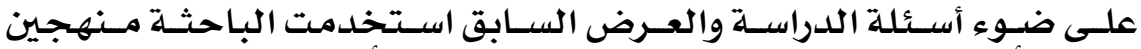

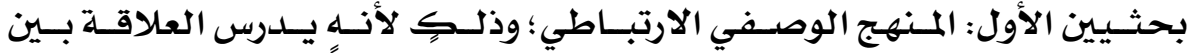

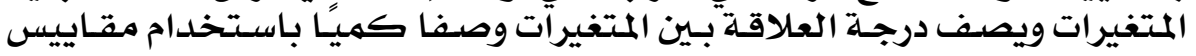

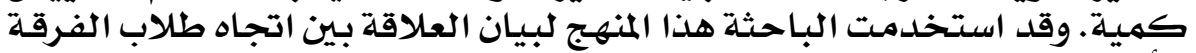

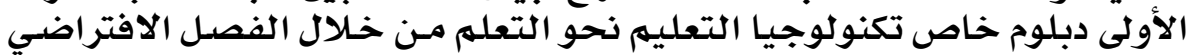

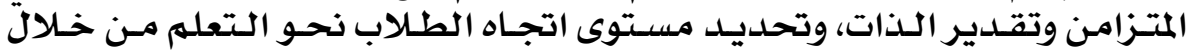

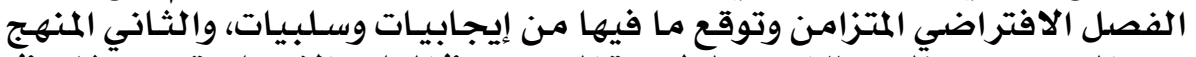

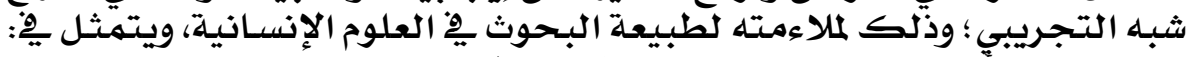

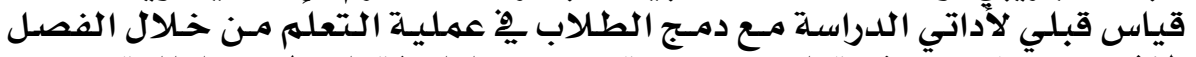

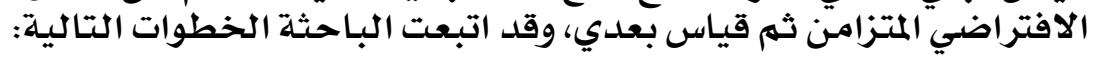

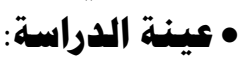

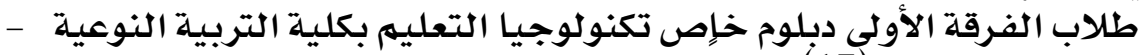

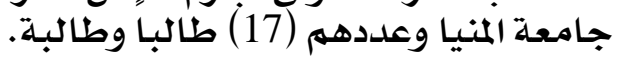
•أدوات الدراسية: • أ-هقياس تقدير الذات (إعداد أحمد هصمد حسن صالح "1990” تعديل ربيع رشوان "†. . ب"):

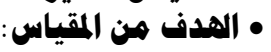

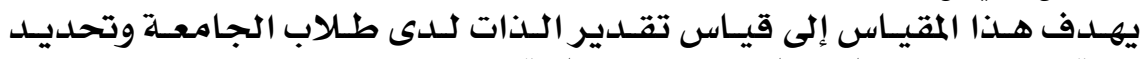

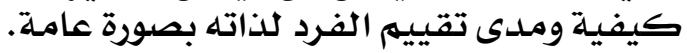

• وصف المقياس:

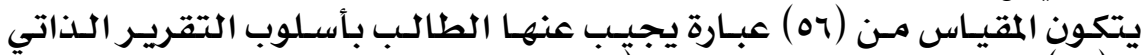

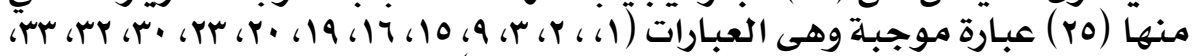

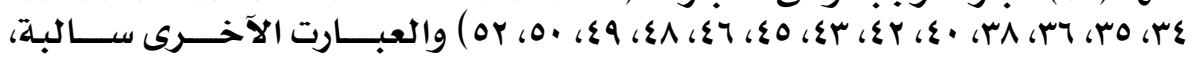

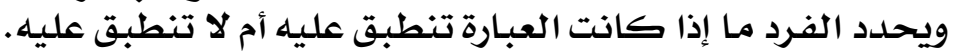

• (تصميح المياس:

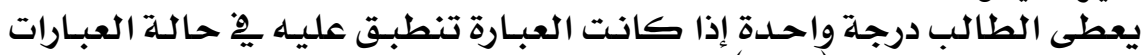

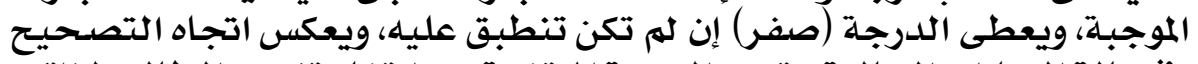

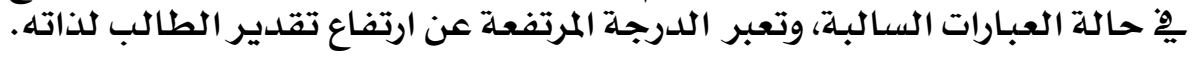

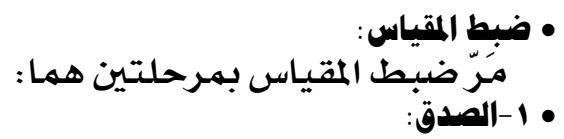

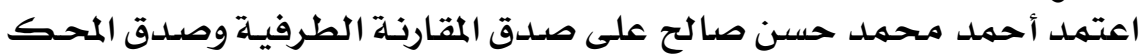

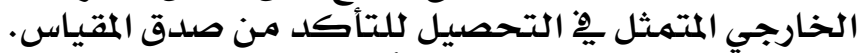

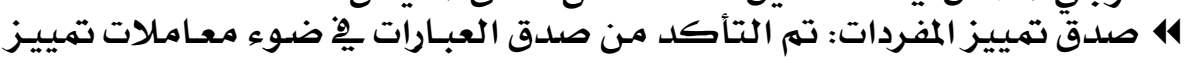

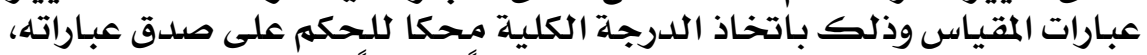

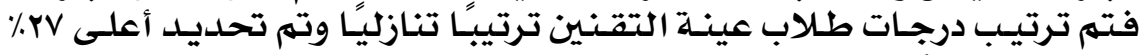

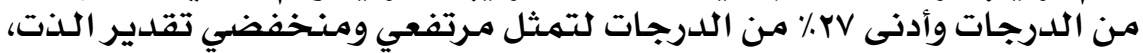

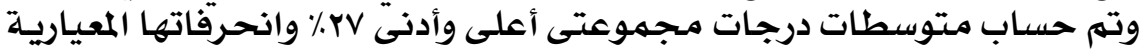

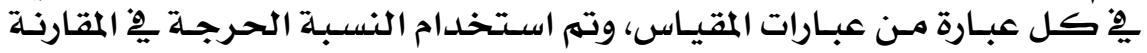

\section{$1 \mathrm{r}$}




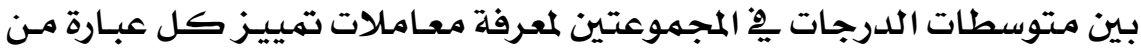

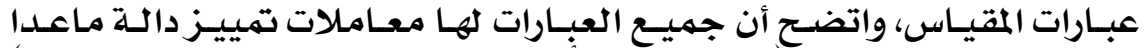

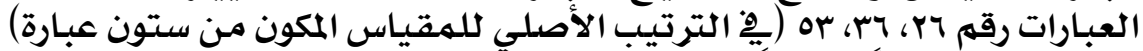

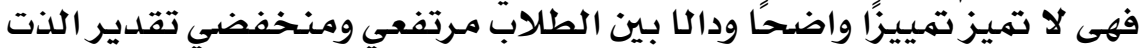

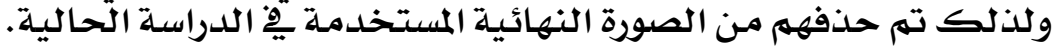

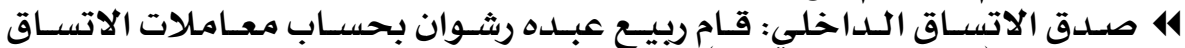

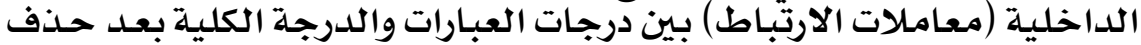

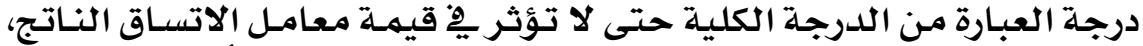

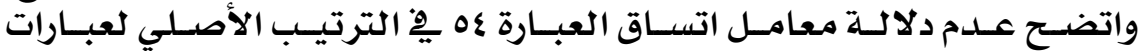

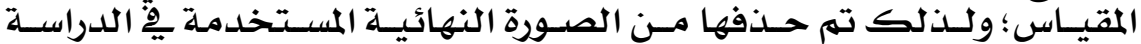

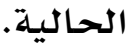

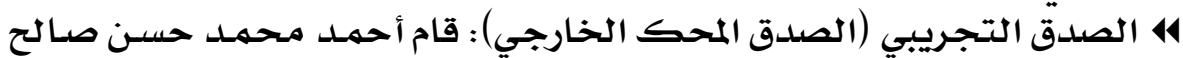

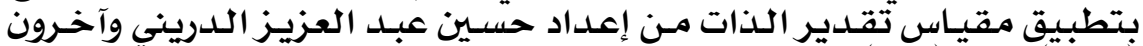

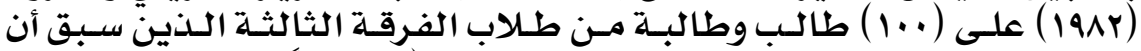

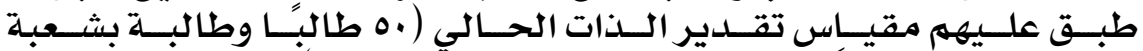

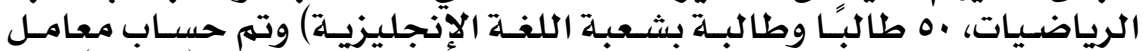

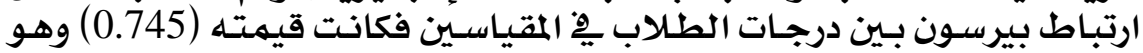
دال عند مستوى (0.01).

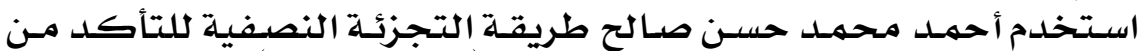

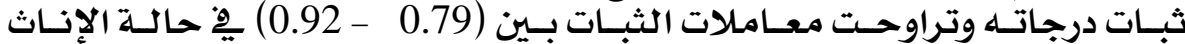

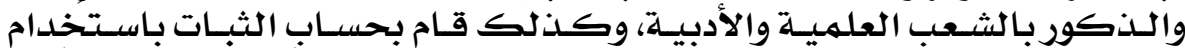

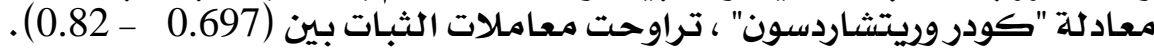

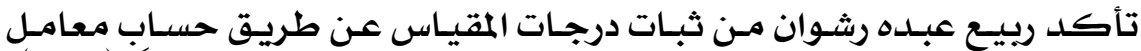

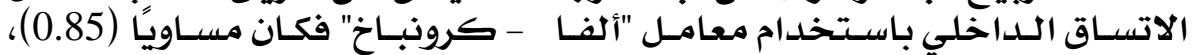

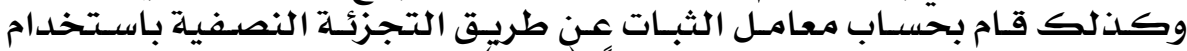

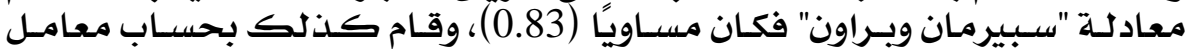

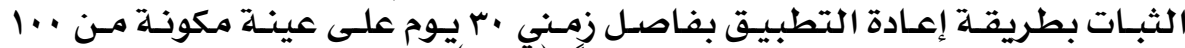

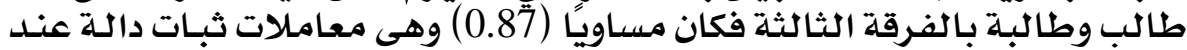
مستوى (0.01).

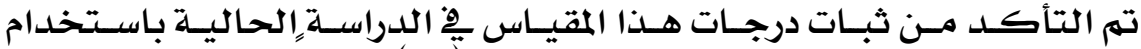

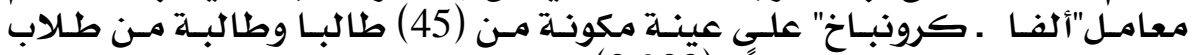

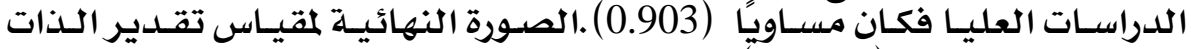
لدى طلاب الجامعة (ملحقق العان ).

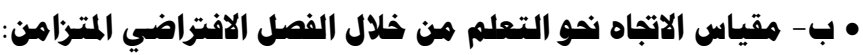

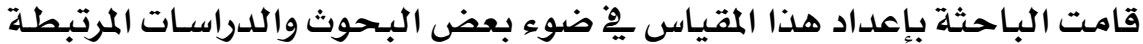
Bolstad \& Lin, ) ،(Chawdhry et al., 2010)،(Heirdsfield et al., 2011) 2009)، وقد مر إعداده بالخطوات التالية: (Heiriele 
• تهديد الهدف هن المقياس :

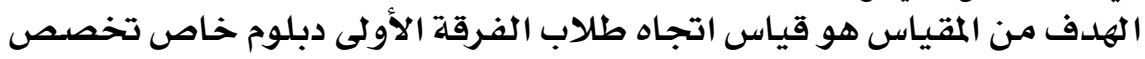

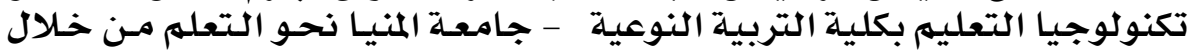

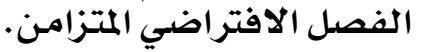

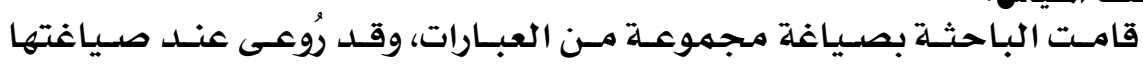

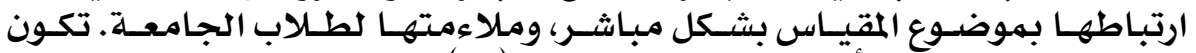

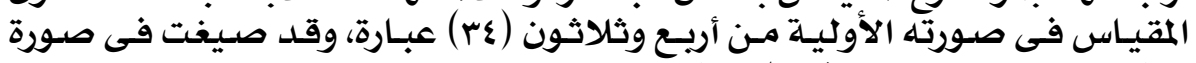

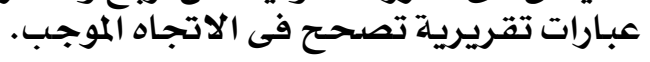
• طريقة تطبيق وتصحيج المقياس :

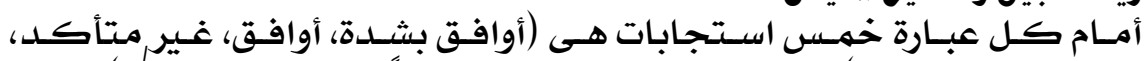

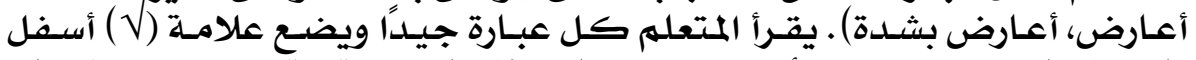

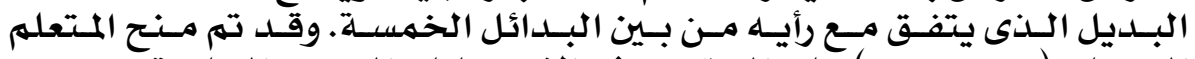

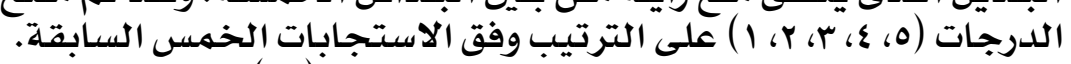

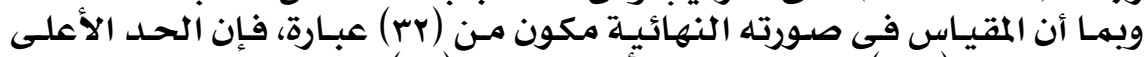

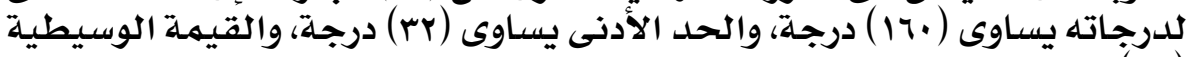

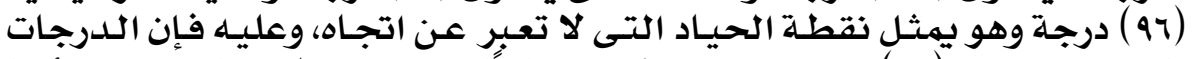

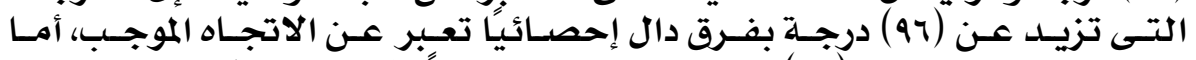

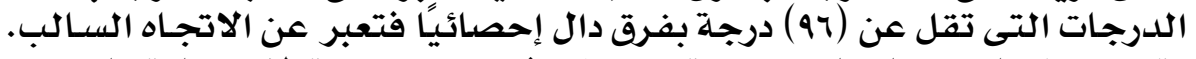

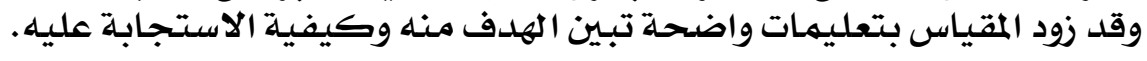

مر ضبط المقياس بهـرحلتين هما :

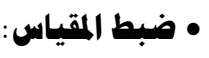

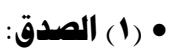

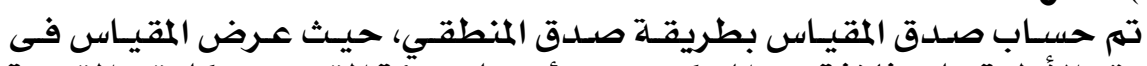

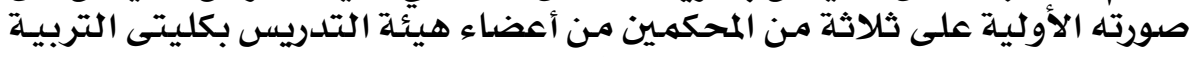

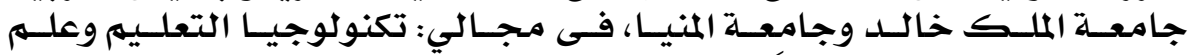

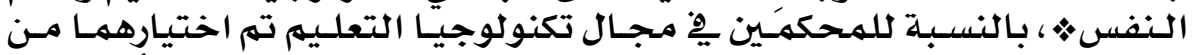

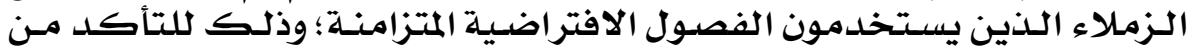

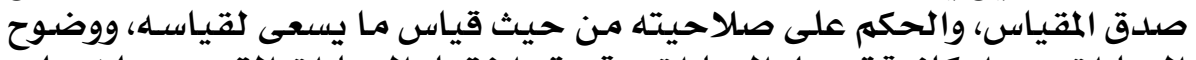

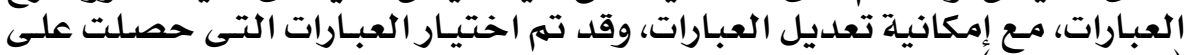

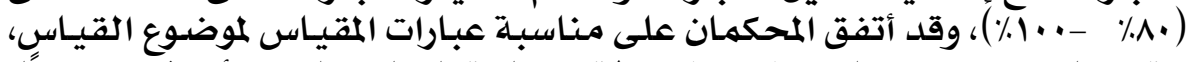

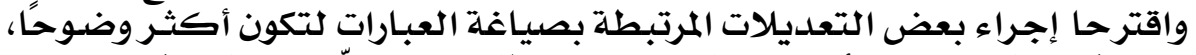

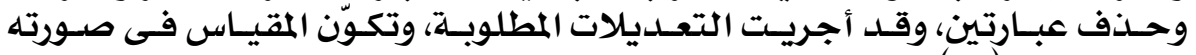

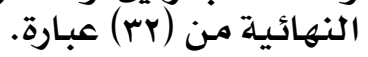

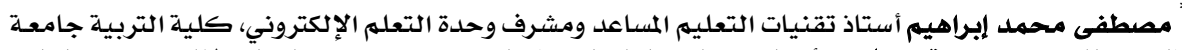

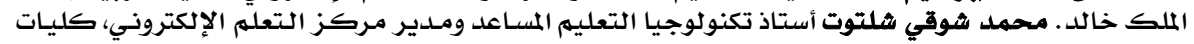

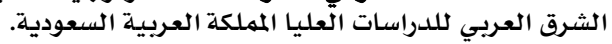

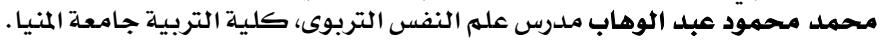

\section{$1 \varepsilon$.}




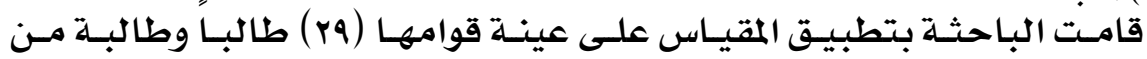

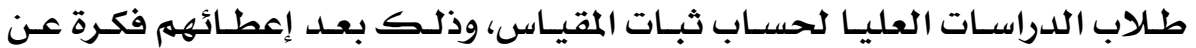

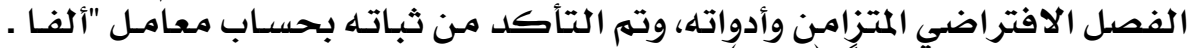

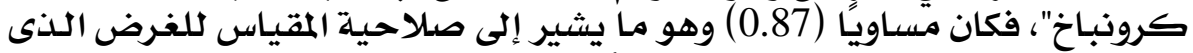

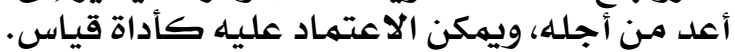

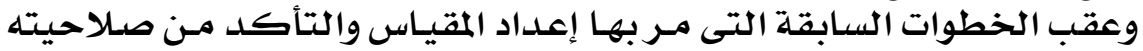

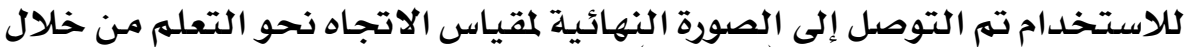

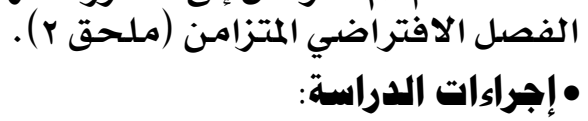

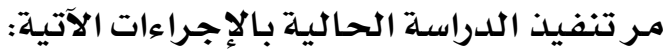

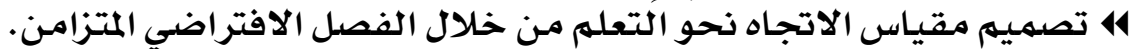

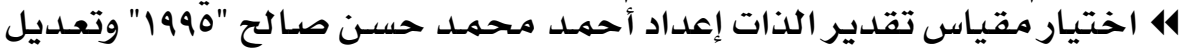

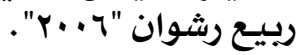

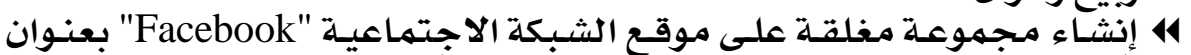

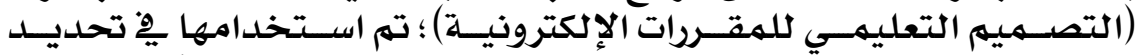

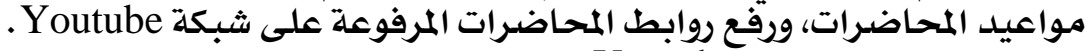

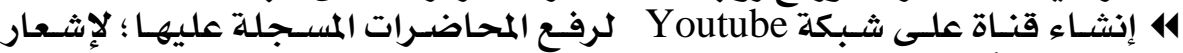

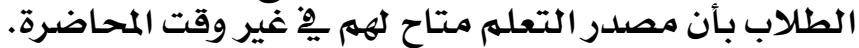

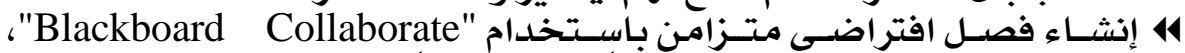

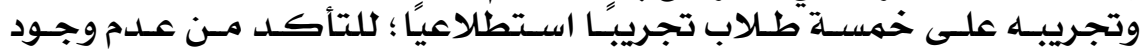

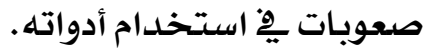

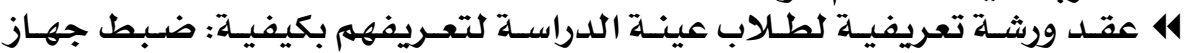

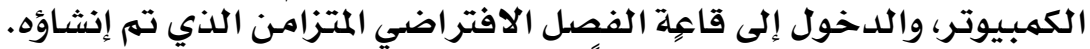

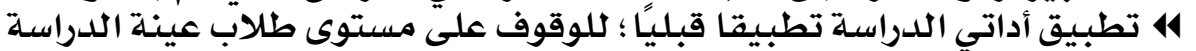

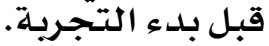

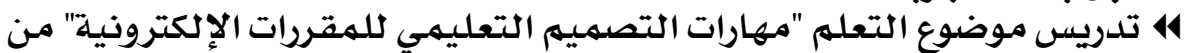

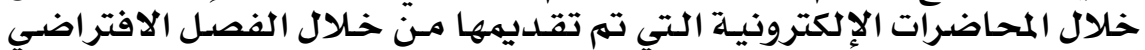

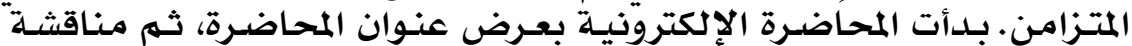

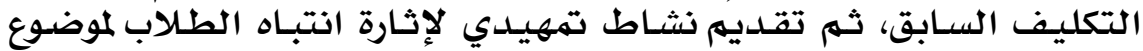

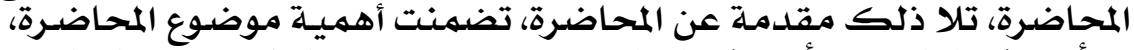

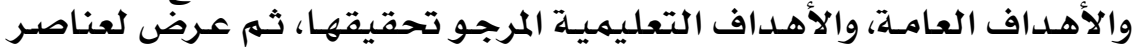

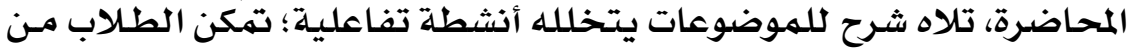

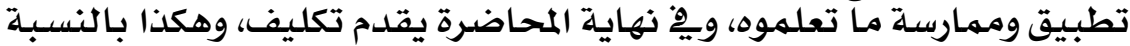

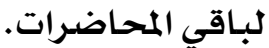

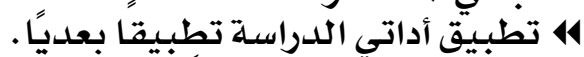

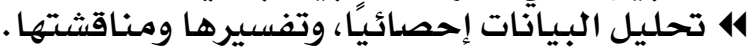

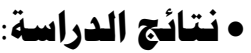

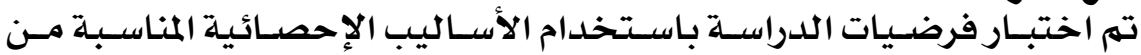

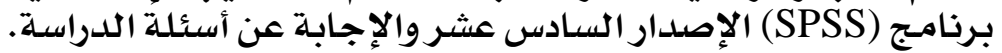

\section{$1 \leqslant 1$}




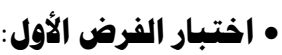

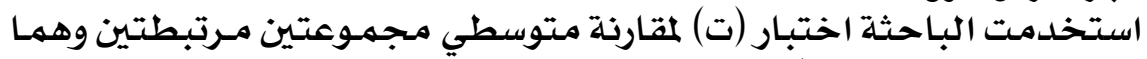

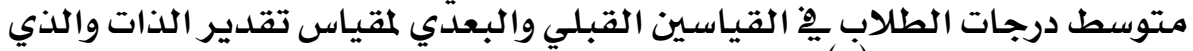

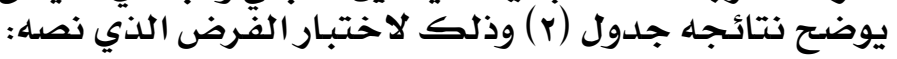

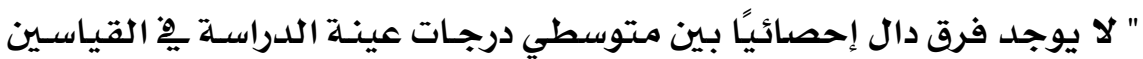

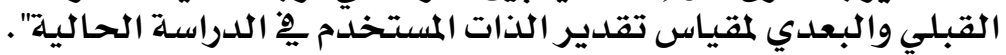

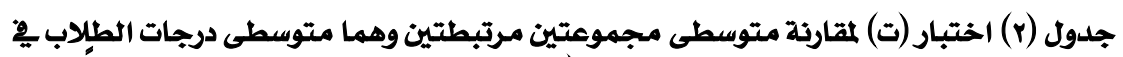

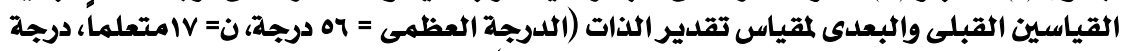

\begin{tabular}{|c|c|c|c|c|c|c|}
\hline حجم التاثير & مريع إيتا & مستوى & قيمة & الانحراف & المتوسط & القياس \\
\hline \multirow{2}{*}{ كبير } & \multirow{2}{*}{0.57} & \multirow{2}{*}{.000} & \multirow{2}{*}{-4.564} & 5.23 & 43.77 & قبلي \\
\hline & & & & 4.56 & 45.24 & بعلىى \\
\hline
\end{tabular}

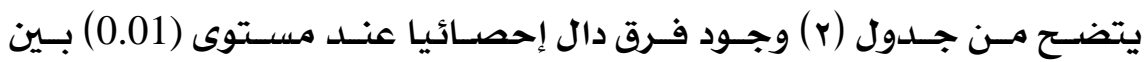

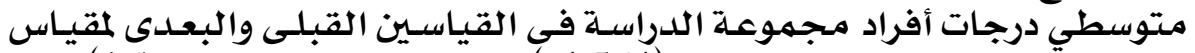

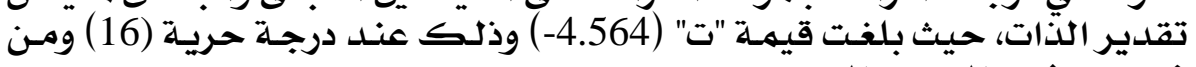

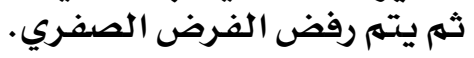

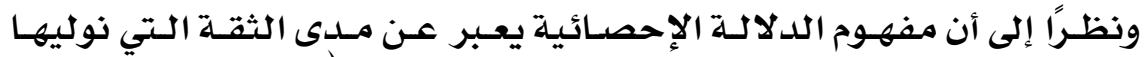

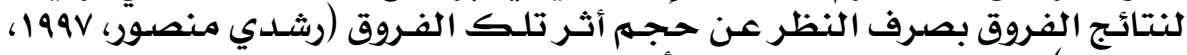

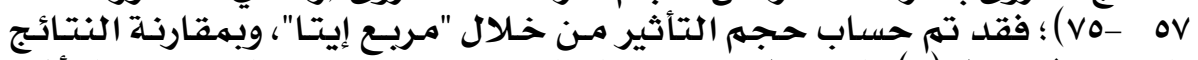

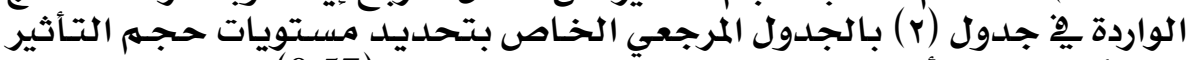

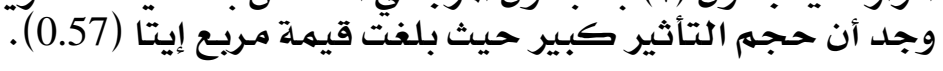

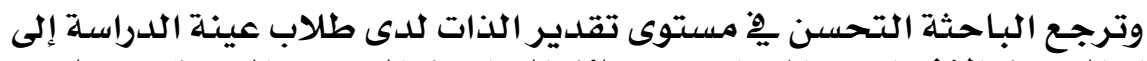

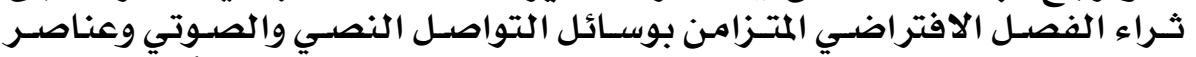

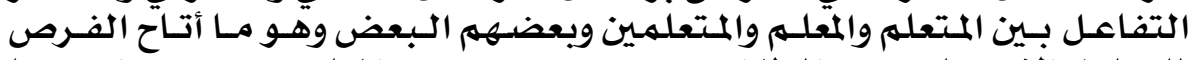

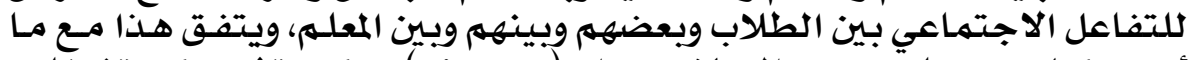

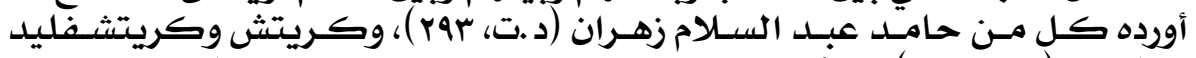

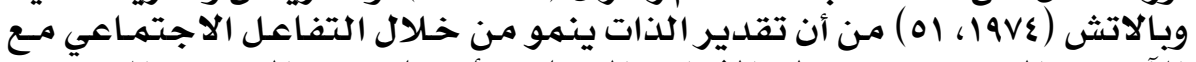

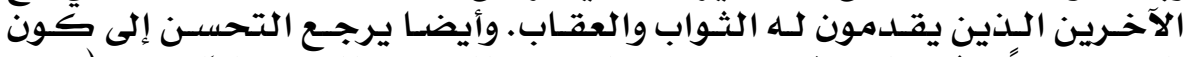

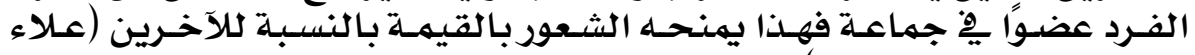

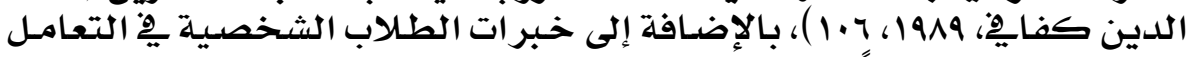

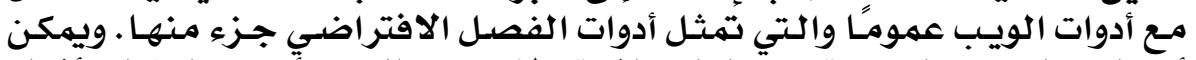

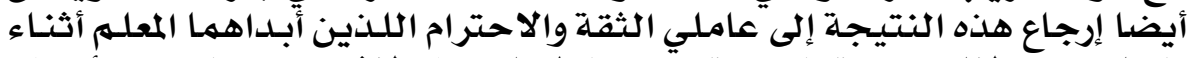

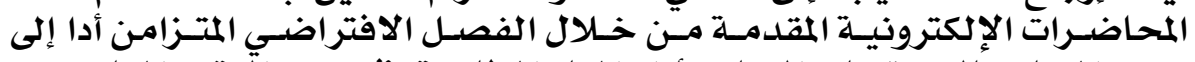

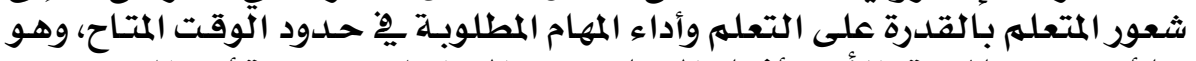

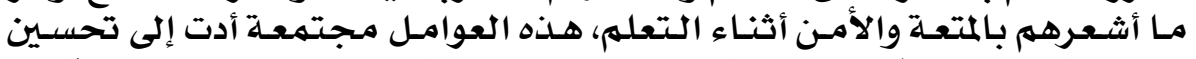

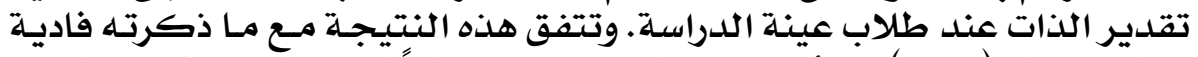

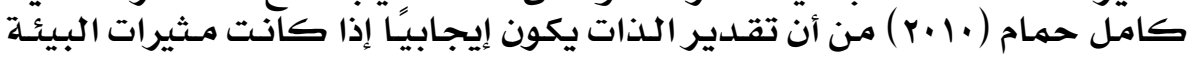

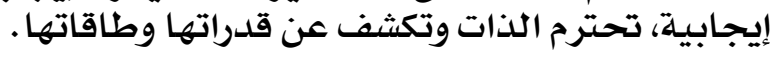

\section{$1 \varepsilon Y$}




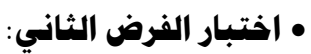

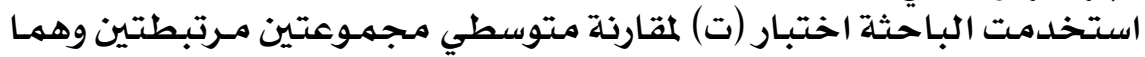

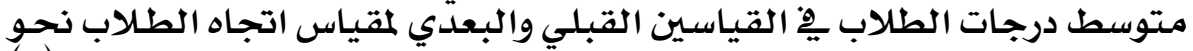

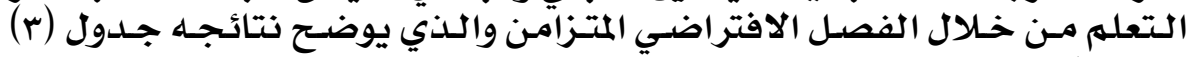

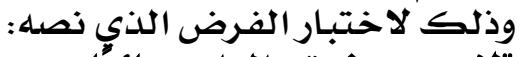

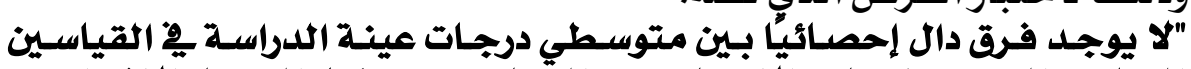

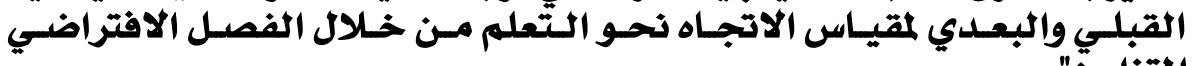

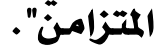

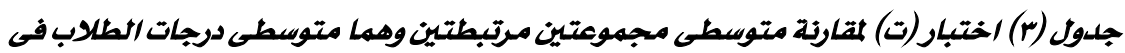

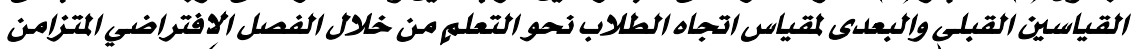

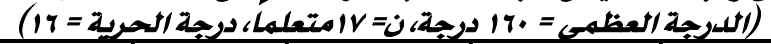

\begin{tabular}{|c|c|c|c|c|c|c|}
\hline حجم التأير & مريع إيتا & مستوى & قيمة & الالانحرافي & المتوسط & القياس \\
\hline \multirow{2}{*}{ كبير } & \multirow{2}{*}{0.89} & \multirow{2}{*}{.000} & \multirow{2}{*}{-11.210} & 7 & 128.18 & قيلر \\
\hline & & & & 10.67 & 142.53 & \\
\hline
\end{tabular}

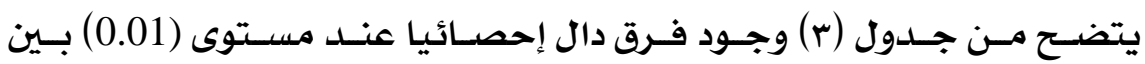

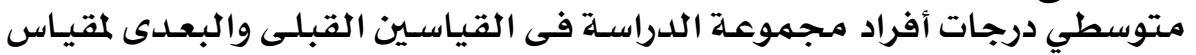

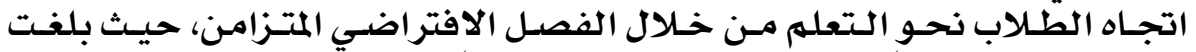

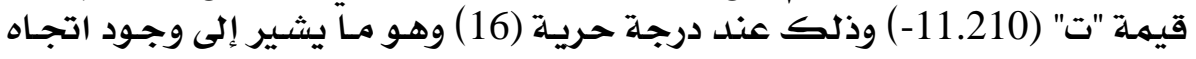

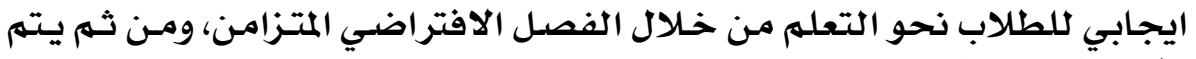

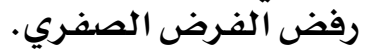

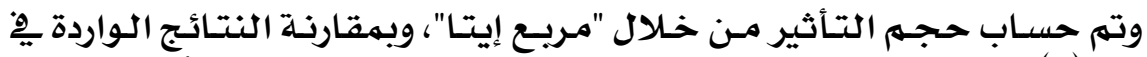

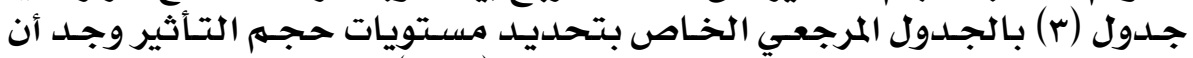

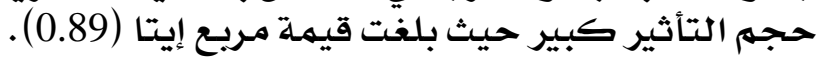

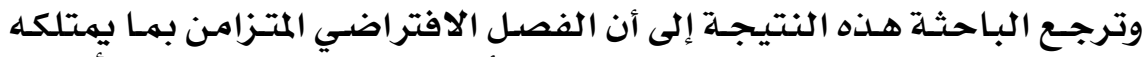

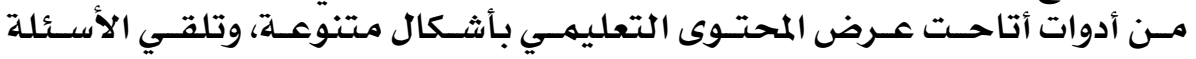

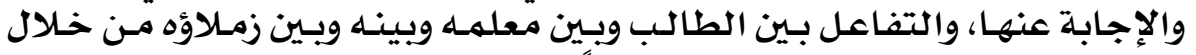

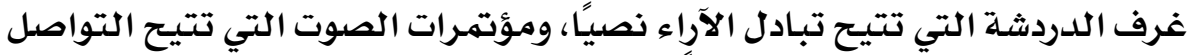

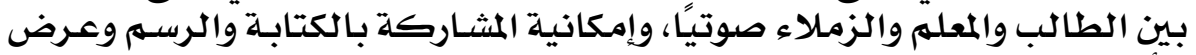

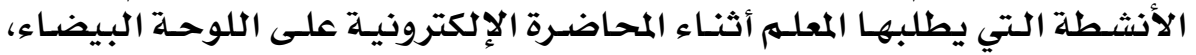

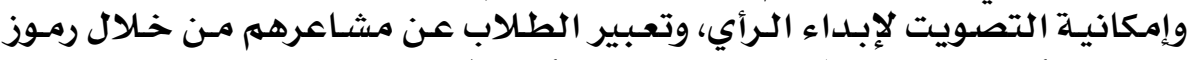

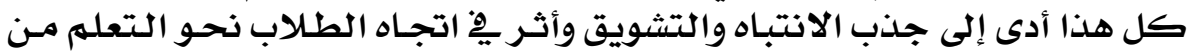

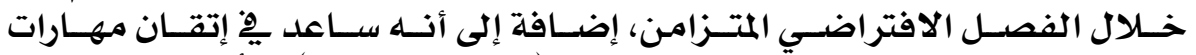

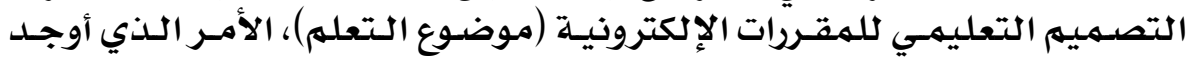

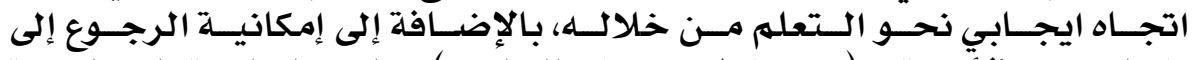

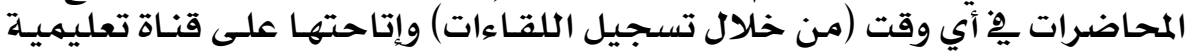

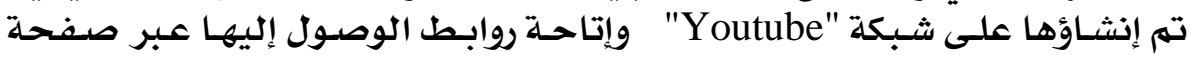

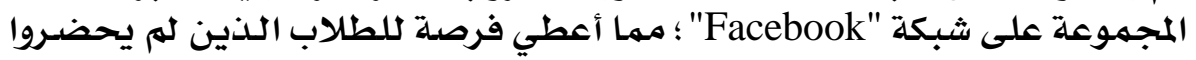

\section{$1 \varepsilon r$}




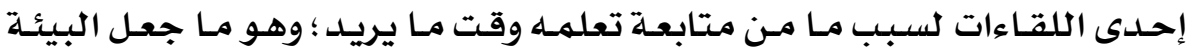

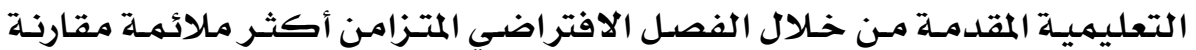

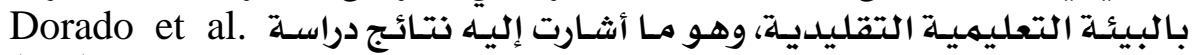

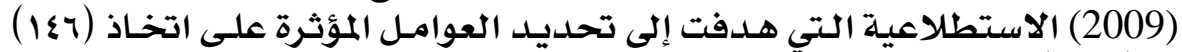

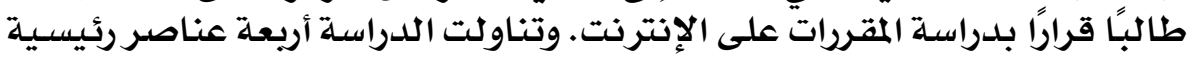

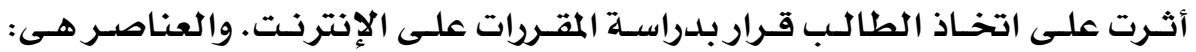

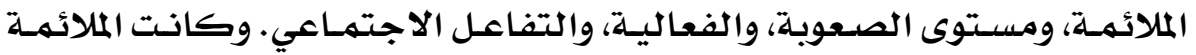

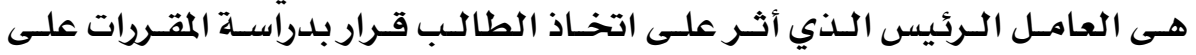

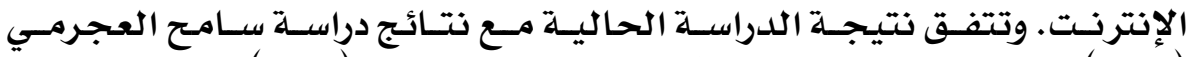

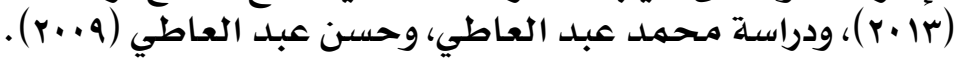

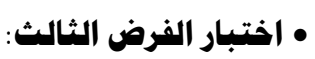

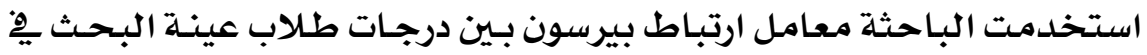

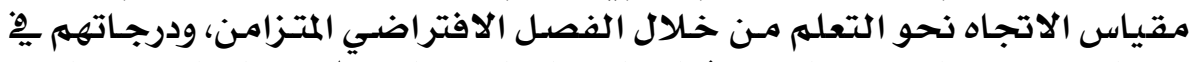

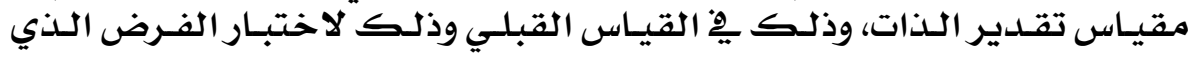
نصديه: تصفياس

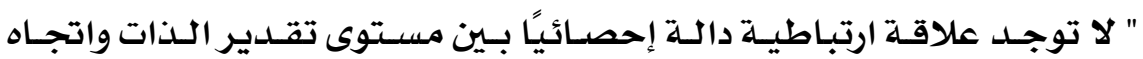

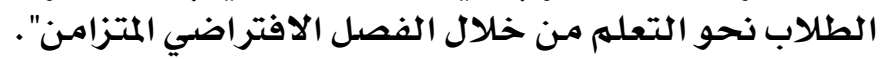

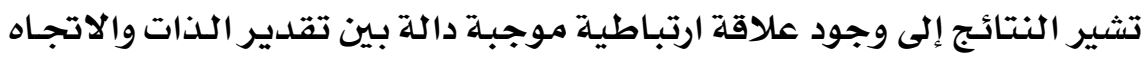

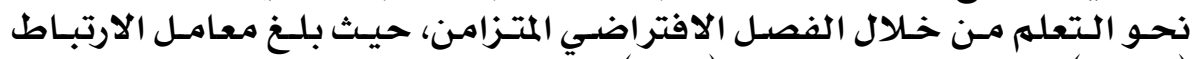

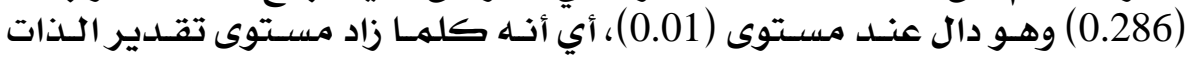

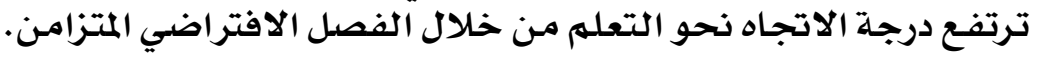

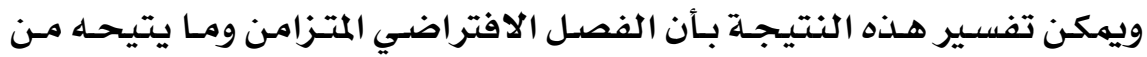

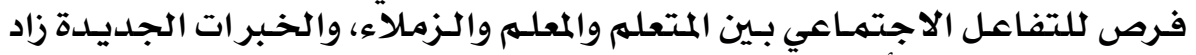

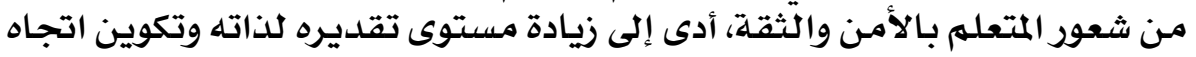

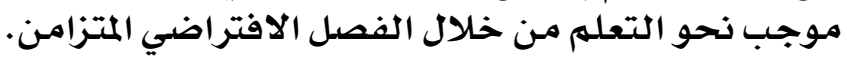
• التوصيات والاقترحات:

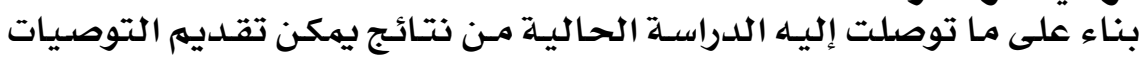

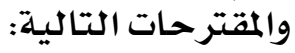
• التوصيات:

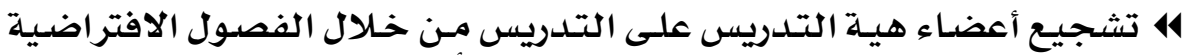

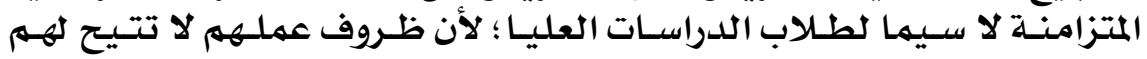

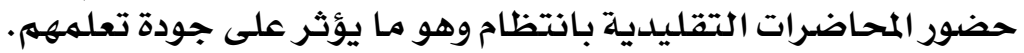

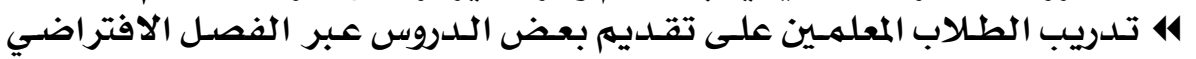
المتززامن.

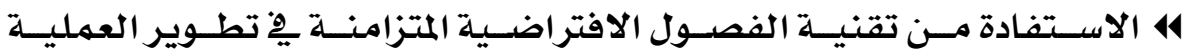

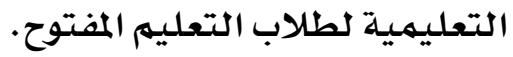

\section{$1 \varepsilon \varepsilon$}


4 إجراء دراسـة على غرار الدراسـة الحالية تستهدف عينات طلابية ِِِ تخصصـات

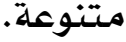

4 دراســة أثـر الفصــل الافتر اضــي المتـززامـن علـى دافعيـة الـتعلهم لـدى طـلاب

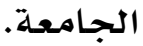

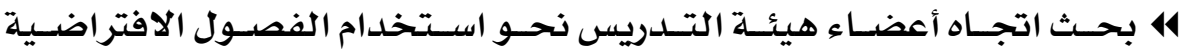

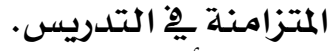

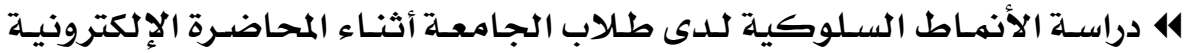

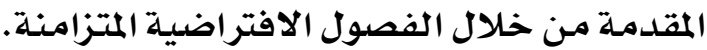

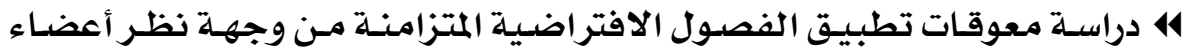

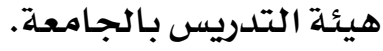

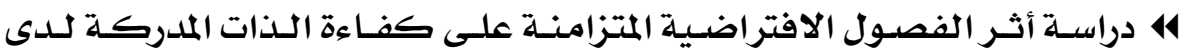

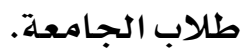

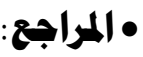

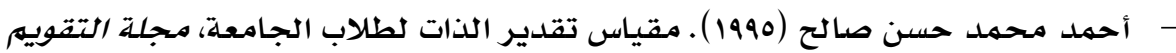

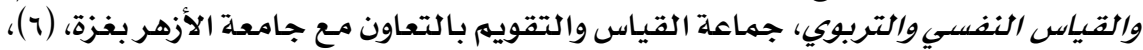
.rYA- Ylo

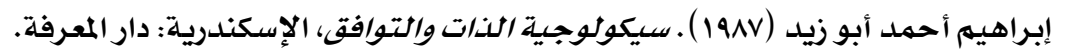

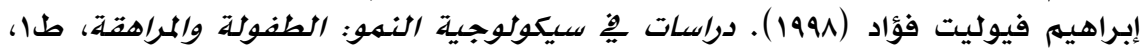

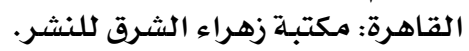

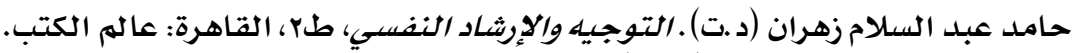

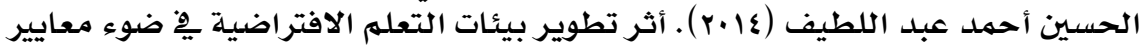

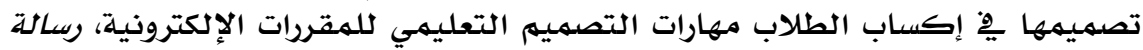

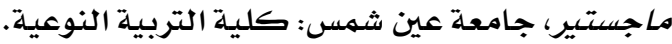

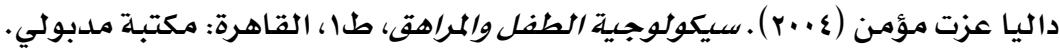

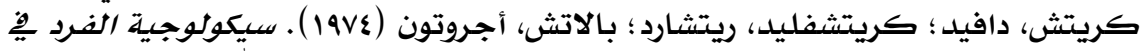

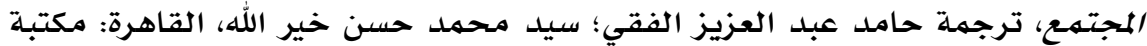

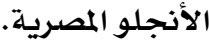

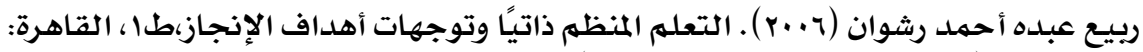

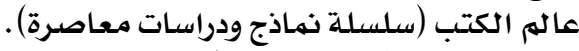

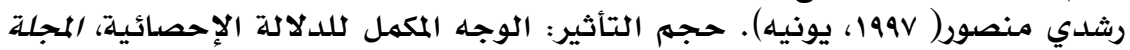

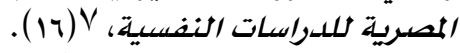

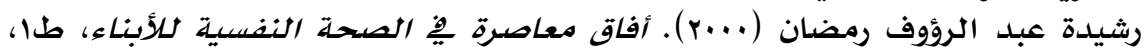

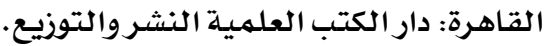

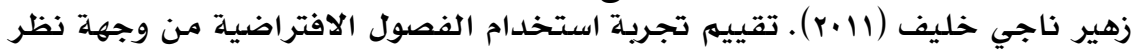

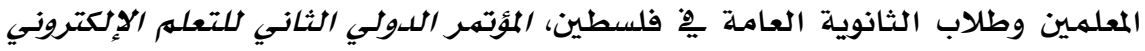

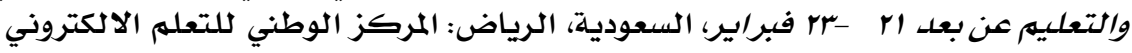
والتدريب عن بعد.

\section{$1 \leqslant 0$}




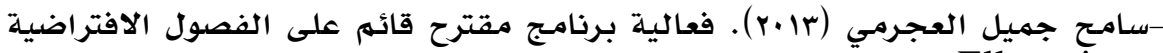
Ellumniate

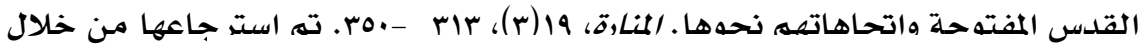

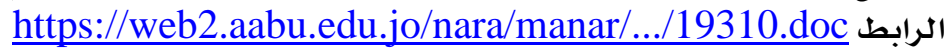

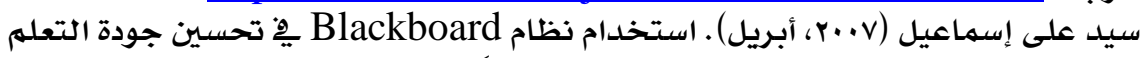

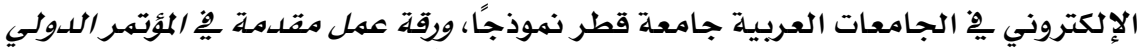

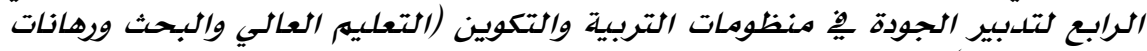

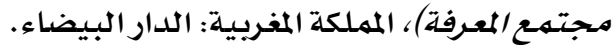

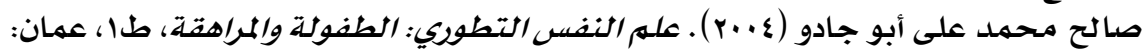

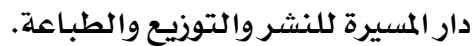

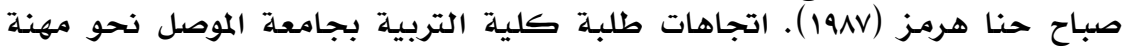

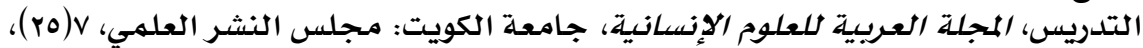
. 1 \& $-11 r$

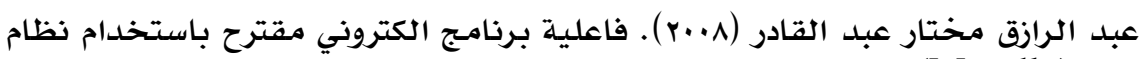

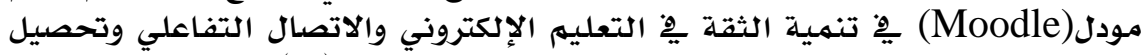

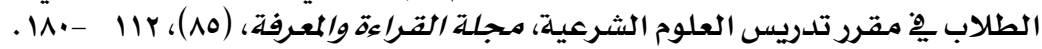

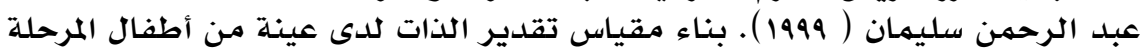

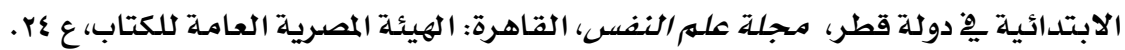

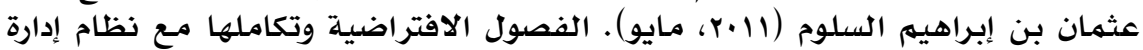
التعله الإنكتروني بـالاك بورد (Blackboard)، دراسات المعلومات، (11)، استرجاعها من خلالال الرابط بلإن بورد

http://informationstudies.net/issue_list.php?action=getbody\&titleid=1 15 علاء الدين كفايْ (1919) . تقدير الذات وعلاقته بالتنشئسة الوالية والأمن النفسي: دراسـة

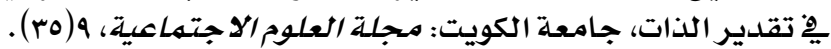

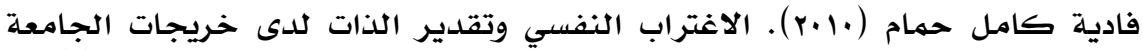

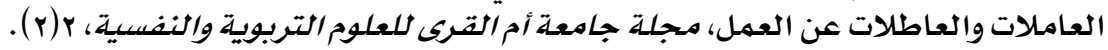

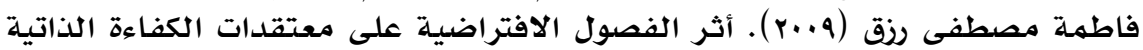

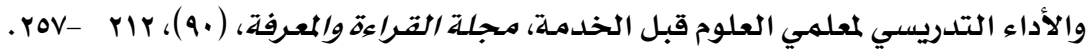

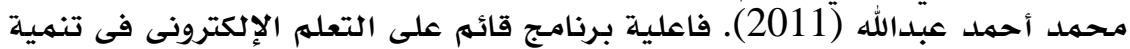

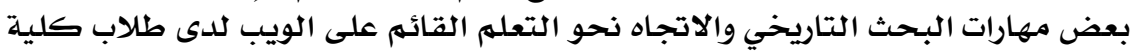

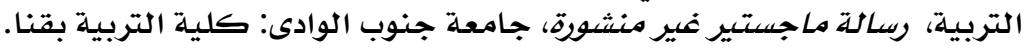

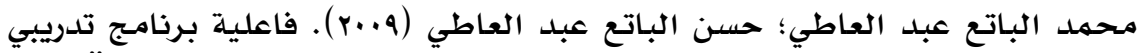

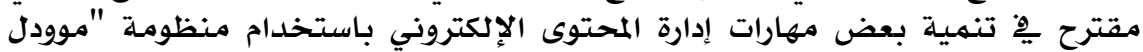

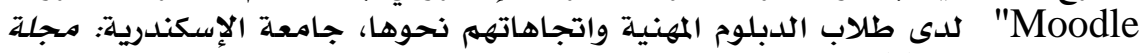

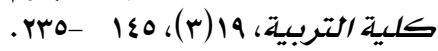

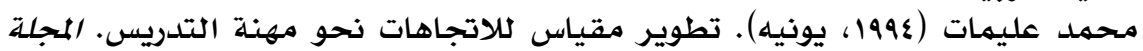

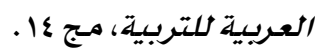

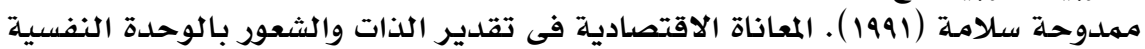

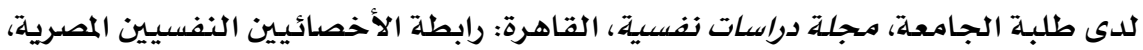

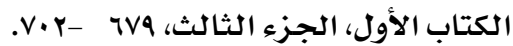


- Abdelaziz, H. A. (2013). From content engagement to cognitive engagement: Toward an immersive Web-based learning model to develop self- questioning and self-study skills. International Journal of Technology Diffusion, 4(1), 16-32.

- Abel, MH. (1996). Self-Esteem: moderator of mediator between perceived Stress and Expectancy. Psychological Reports, 79(2), 635641.

- Bailey, J.G. (1999). Academics' motivation and self-efficacy for teaching and research. Higher Education Research \& Development, 18(3), 343-359.

- Bednar, R. L., Peterson, S. R. (1995). Self-Esteem: Paradoxes and innovations in clinical theory and Practice ( $2^{\text {nd }}$ ed.). Washington, DC: American Psychological Association.

-Brehm, S., \& Kassin, S. (1996). Social psychology (3rd ed.). Houghton Mifflin College Division: the University of Michigan.

-Bolstad , R., \& Lin, M. (2009). Students' experiences of learning in virtual classrooms, Final report prepared for the Ministry of Education.

Retrieved

from http://www.nzcer.org.nz/system/files/students-experiences-learningvirtual-classrooms.pdf

-Chawdhry, A. A., Paullet, K., \& Benjamin D. (2010). Assessing Blackboard: Student Perceptions of the Online Tool. Issues of Information Systems Journal, 11(1), 518-524. Available at: iacis.org/iis/2010/518-524_LV2010_1434.pdf

-Chawdhry, A. A., Paullet, K., \& Benjamin, D. (2011). Assessing Blackboard: Improving Online Instructional Delivery. Information Systems Education Journal (ISEDJ), 9(4), 20-26. Retrieved from http://isedj.org/2011-9/N4/ISEDJv9n4p20.pdf

- Dorado, C., Hernandez, J., Sani, B., Griffin, C., \& Barnett, W. (2009). An exploratory analysis of factors influencing students decisions to take online courses. Issues in Information Systems, 10(1), 183-190.Retrieved from http://iacis.org/iis/ 2009/ P2009 1274.pdf

-Heirdsfield, A., Walker, S., Tambyah, M., \& Beutel, D. (2011). Blackboard As An Online Learning Environment: What Do Teacher 


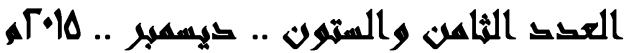

Education Students And Staff Think? Australian Journal of Teacher Education, 36(7), 1-16. Retrieved from

- http://ro.ecu.edu.au/cgi/viewcontent.cgi?article=1603\&context=ajte

- Martin, F., Parker, M., \& Allred, B. (2013). A Case Study on the Adoption and use of Synchronous Virtual Classrooms. The Electronic Journal of e-Learning, 11(2), 124-138. Retrieved from www.ejel.org/issue/download.html?idIssue $=25$

-Parker, M. A., \& Martin, F. (2010). Using virtual classrooms: Student perceptions of features and characteristics in an online and a blended course. MERLOT Journal of Online Learning and Teaching, 6(1), 135-147. Retrieved from

http://jolt.merlot.org/vol6no1/parker_0310.htm

- Weiten, W., \& Lloyd, M. (1997). Psychology applied to modern life: adjustment in the 90s (5th ed.). Pacific Grove, Ca: Brooks/Cole publishing company. 